\title{
Tsunami risk reduction for densely populated Southeast Asian cities: analysis of vehicular and pedestrian evacuation for the city of Padang, Indonesia, and assessment of interventions
}

\author{
Manuela Di Mauro • Kusnowidjaia Megawati • Veronica Cedillos • \\ Brian Tucker
}

Received: 25 September 2012/ Accepted: 4 March 2013/Published online: 16 March 2013

(C) Springer Science+Business Media Dordrecht 2013

\begin{abstract}
A major tsunamigenic earthquake is expected in the near future along the coast of West Sumatra Province of Indonesia. In the city of Padang, the arrival time of the tsunami is expected to be $\sim 30 \mathrm{~min}$. Currently, there are approximately 400,000 people in the city living within the potential inundation zone. This study aimed to complement the existing research in appraising possible risk reduction interventions, specifically looking at enabling the timely evacuation of the area. This research, developed in consultation with national and local authorities, emergency planners and NGOs, analysed interventions for tsunami risk reduction in Padang through the development of a pedestrian and vehicular evacuation model and the appraisal of possible solutions to enhance the evacuation rates. Some of the conclusions from this research can be applied to other areas in Southeast Asia where the traffic patterns are similar to those in Padang and where the distance to safety is greater than 4-5 km. For the case of Padang, the results show that pedestrian evacuation is strongly preferable to vehicular evacuation due to the limited road capacity and the high population density. In the present situation, however, $70-80 \%$ of the population in Padang could not evacuate within $30 \mathrm{~min}$, even by foot. Common interventions such as widening roads and building bridges prove to be relatively ineffective in this case due to the large distance that has to be covered in a short time. These interventions would only have a decisive impact if a longer evacuation time was available (more than $60 \mathrm{~min}$ ). In the case of Padang, the evacuation rate in the first $30 \mathrm{~min}$ is strongly dependent on the presence/absence of evacuation shelters, whose effectiveness is limited by the capacity of the structures. Building a few highcapacity and high-resilience structures such as evacuation hills is a more effective and robust
\end{abstract}

M. Di Mauro

Earth Observatory of Singapore, Nanyang Technological University, Singapore, Singapore

M. Di Mauro ( $\square)$

United Nations Office for Disaster Risk Reduction, Geneva, Switzerland

e-mail: dimaurom@un.org

K. Megawati

Civil and Environmental Engineering, Nanyang Technological University, Singapore, Singapore

V. Cedillos · B. Tucker

GeoHazards International, Palo Alto, CA, USA 
evacuation strategy than constructing many small high-raised buildings. Even with evacuation structures, wider roads and bridges, about $20 \%$ of the population would still be unable to reach safety by the time the tsunami arrives. This means about 70,000 people of Padang's current population, which is rapidly increasing. The building of evacuation shelters may be a viable option for saving lives in the short term, but it is not a sustainable option in the medium to long term. It is therefore also necessary to set up and enforce regulations for land use planning that take into account the tsunami risk and prevent further urban development for the areas that may be affected by a tsunami.

Keywords Tsunami - Disaster risk reduction · DRR · DRR interventions · Evacuation $\cdot$ Vertical evacuation $\cdot$ Evacuation modelling

\section{Introduction}

The city of Padang, West Sumatra, is likely to be affected by a tsunamigenic earthquake of magnitude $\sim 8.9$ within the next few decades (Avouac et al. 2008). The arrival time of this potential tsunami has been estimated to be between 21 (McCloskey et al. 2008) and 65 min (Taubenbock et al. 2009) after the earthquake occurs, with the average arrival times calculated as $30 \mathrm{~min}$ (Muhari et al. 2010) or $35 \mathrm{~min}$ (Borrero et al. 2006). The estimated maximum inundation depth varies from $6 \mathrm{~m}$ (Muhari et al. 2010; Borrero et al. 2006), $8 \mathrm{~m}$ (Muhari et al. 2010) to approximately $12 \mathrm{~m}$ (Gayer et al. 2010). The population of Padang is approximately 833,562 inhabitants (BPS Kota Padang 2010), with an average density of about $4,000 \mathrm{in} / \mathrm{Km}^{2}$, with peaks of almost $40,000 \mathrm{in} / \mathrm{Km}^{2}$ (calculated from MapAction 2009, and Lammel et al. 2010). With these figures, Padang is considered one of the cities currently facing the highest tsunami risk in the world (USGS 2010).

Despite a general agreement among the scientific community regarding the need of implementing risk reduction interventions quickly, the research for reducing the risks from such event has been, up until now, incomplete. The description of the potential earthquake and tsunami hazards is extensive (e.g. Natawidjaja et al. 2006; Sieh et al. 2008; Avouac et al. 2008). The assessment of possible consequences (Post et al. 2009; Lammel et al. 2010; Imamura et al. 2012), however, is currently limited, and the existing research has failed to adequately communicate the results, especially in terms of the likelihood of the population evacuating before the tsunami reaches the coast. The research described in this paper aims to analyse the gaps in these existing studies and provide scientifically sound evidence for the government to support and promote the implementation of interventions. This study also provided general conclusions regarding evacuation patterns and impacts of interventions for reducing tsunami risk, which can inform disaster management scientists and practitioners. This paper is structured as follows:

- Review of previous work on assessing evacuation scenarios in Padang and evaluation of the eventual gaps that need to be covered to adequately inform the implementation of risk reduction measures.

- Description of the outcomes from the consultations with stakeholders involved in emergency management at the national and local level. This consultation aimed to understand what evidence was needed to support the implementation of risk reduction measures.

- Investigation of the current emergency evacuation procedures and previous events to characterise possible evacuation patterns. 
- Rationale of the model developed to represent the local traffic conditions and the possible evacuation scenarios.

- Analysis of the model's results and translation into recommendations to reduce the tsunami risk in Padang.

\section{Review of previous work on tsunami evacuation assessment for Padang}

The work of Lammel et al. (2010), Post et al. (2009) and Imamura et al. (2012) constitutes the most relevant and up-to-date research in tsunami risk assessment for Padang.

Lammel et al. (2010) developed a pedestrian evacuation model by adapting a MatSIM queuing vehicular model, using Weidman's fundamental diagram (Weidman 1993). This model is able to simulate a large number of pedestrians and calculate pseudo-optimal solutions through an iterative process that stops when the 'Nash equilibrium' is reached. The model includes only pedestrians' movement. Looking at the 'optimal' solutions does not account for more complex scenarios and might produce an overly optimistic solution. In fact, this study concluded that an evacuation would be possible within $30 \mathrm{~min}$. Although the authors agree that this solution is achievable only with considerable training (Lammel et al. 2010), in practice it would imply the adoption of 'personal evacuation plans', meaning that each individual should follow a plan that potentially differs from that of his/ her neighbour. However, many cognitive studies have demonstrated that during an evacuation, people tend to be influenced by the behaviour of those around them (Latane 1979; Turner 1964). This solution is far from being realistically implementable from an operational perspective, especially under the 30-min time constraint and following a strong earthquake. This model does not include the delay at the intersections, which can lead to a potentially important underestimation of evacuation times.

Another study developed by Post et al. (2009) proposes a GIS-based tool that calculates possible evacuation times based on the physical distances to safe places, land use and population characteristics, which are then weighted to calculate potential evacuation speeds. These evacuation speeds, compared with the length of artificial evacuation routes (that do not correspond to physical roads but are obtained by applying a cost-distance algorithm), provide a distribution of the evacuation times. The detailed results from this study are reported in Imamura et al. (2012) and show that about $100 \%$ of the population is able to evacuate within $30 \mathrm{~min}$. 'If the assumed threshold of tsunami arrival time is $20 \mathrm{~min}$, only 100,847 people of a total 146,364 people exposed by tsunami hazard are estimated to be able to get out of the tsunami inundation zone' (Imamura et al. 2012). As the same authors suggest, these results are an overestimation of the number of evacuees that can reach safety, as there is no attempt made to account for pedestrian traffic conditions, which would translate in lower individual evacuation speeds due to the limited road capacity. Also, these results only cover the southern part of the city, in which the total population is approximately 210,421 people. The study of Post et al. (2009) assumes that only those who are located exactly within the (potential) inundation area should evacuate (146,364 people). However, due to the differences in the modelling approaches and assumption, it is risky to consider the area immediately outside the extent of the inundation as 'safe'. Also, other arguments can be made suggesting that this assumption is not acceptable for operational and behavioural reasons. For example, it implies knowing the exact extent of the inundation area, thus suggesting that the people not in this immediate area should stay put. This is obviously a controversial decision given the uncertainties of the inundation boundary. It is also very unlikely that the people that 
are not evacuating would stay put and watch others evacuating (e.g. Parker et al. 2009; Trajfel 1978; Turner 1964).

A more recent study carried out by Imamura et al. (2012) presents another pedestrianonly evacuation model developed using the NetLogo modelling platform. The movement of the people is modelled by using the Predictive Collision Avoidance model and the corridor test of Helbing and Treiber (1999). Similarly to Lammel et al. (2010), this model does not take into account any delay at the intersections. The modelled area only includes the very southernmost part of the city (104,352 people). The authors also divide the analysed area into three smaller subareas for computation reasons. This might have led them to overlook important bottlenecks occurring longitudinally, especially those caused by people evacuating towards the hill located in the southernmost part of the area. Despite the limitations, the results from Imamura et al. (2012) show evacuation times rather more consistent with the area's population figures and density compared to the other two studies.

The current published research thus presents these gaps:

- The first two studies assessed evacuation times that are very likely to be underestimated and disseminated them to the local and national emergency planning agencies and the stakeholders, with potentially important consequences in terms of risk perception.

- All the three studies focus only on pedestrian evacuation, misrepresenting the real situation (heavy vehicular traffic), and therefore to underline the advantages and disadvantages of using vehicles to evacuate.

- These studies did not produce evidence showing the effects of possible risk reduction strategies and their benefits, so that can be used to support possible interventions.

These gaps indicate the need of further analysis of these issues. This study was carried out as a complementary to these previous studies. The aims were to provide realistic results, analysing possible evacuation scenarios and assessing the benefits of disaster risk reduction interventions.

\section{Consultation work}

The basis for any research on evacuation is to gain an initial appreciation of the current conditions, in terms of risk perception, possible responses, local traffic patterns and current evacuation procedures. As part of this research, extensive consultations with local actors involved in emergency planning and response were carried out. The aim of this consultation work was also to identify the needs for evidence regarding evacuation management and interventions. The first round of consultations identified the main actors that were to be engaged for further consultations. The list of the consulted organisations and the summary of their input to this study are shown in Table 1 . The consultation was carried out through semi-structured interviews aimed at encouraging a spontaneous dialogue with the consultees. The main points that emerged from the consultation were as follows:

- During the previous mass evacuations following the 2009 Padang earthquake and the 2012 Northern Sumatra earthquake, people mostly evacuated by vehicles and caused severe traffic jams (based on consultation with BPBD and Kogami, and also widely reported in the news).

- The local emergency planners (BPBD) expressed the need to analyse the evacuation for the northern part of the city, which was not covered by any previous models, and as a result, specific evacuation options were not available. 


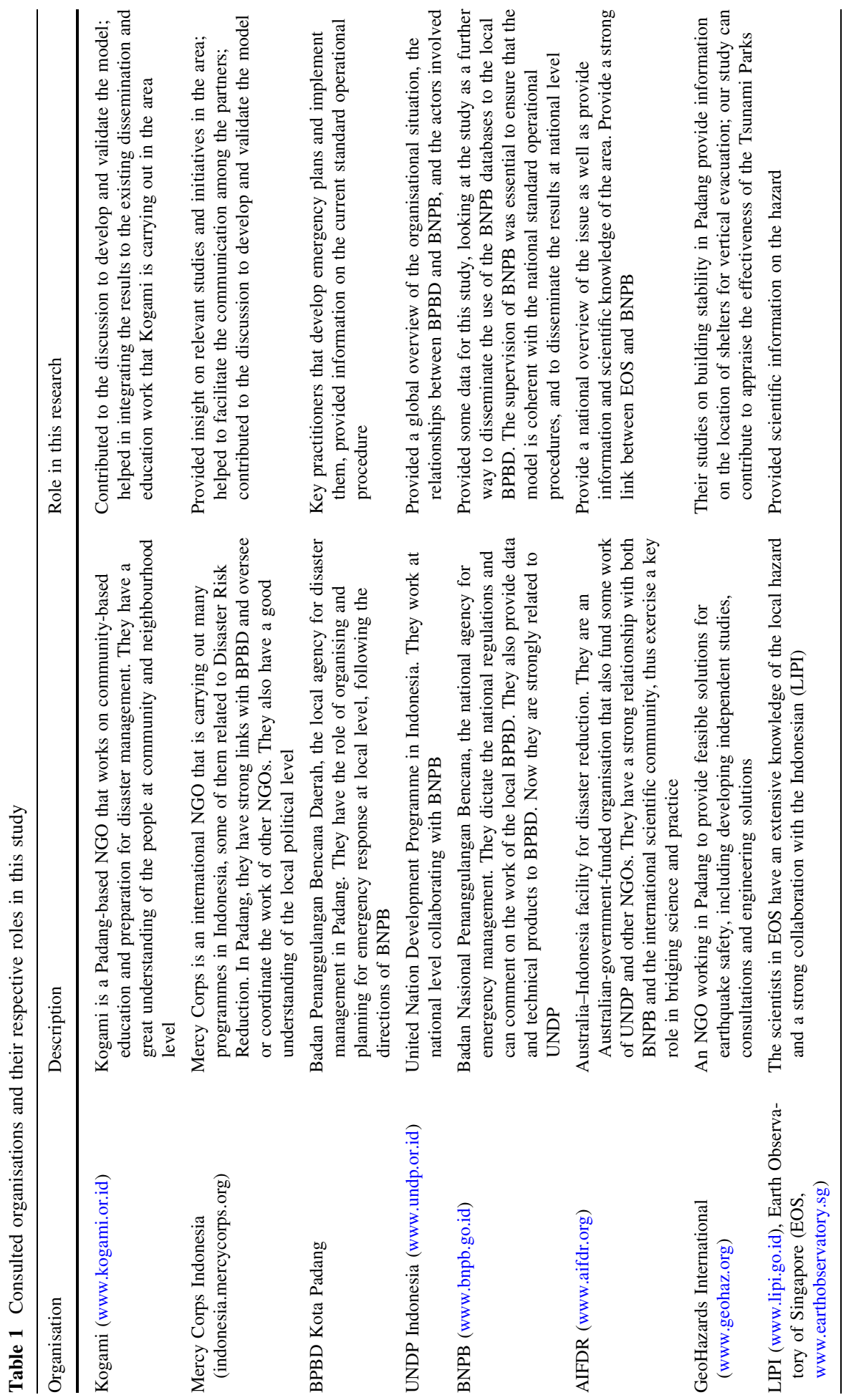


- From the interviews with BPBD and the national disaster management agency (BNPB), it emerged that the results from the model by Post et al. (2009) were interpreted by some officials as the actual feasibility, given the current situation, of evacuating the southern part of the city within $30 \mathrm{~min}$.

- The comprehensive work carried out by GeoHazards International includes the identification of possible sites for building vertical evacuation structures in the form of Tsunami Parks (see also Cedillos 2011). However, there have been issues regarding the land ownership that can only be solved with the support of the local government.

- The national disaster management agency (BNPB) seems to embrace the idea of constructing vertical evacuation buildings (from consultation with BNPB and the Australian Indonesian Facility for Disaster Reduction; also see Bappena and BNPB 2010).

- As part of their education programmes, Kogami encourages evacuation by foot; they also promote the building of new roads and the widening of existing ones to facilitate the evacuation. They pointed out that the population might not 'trust' the use of vertical evacuation buildings due to their eventual unreliability after an earthquake.

- From the consultation with BPBD and Kogami, it emerged that some of the communities have prepared community evacuation plans, in which the evacuation roads are discussed and decided by the community at neighbourhood scale. This means that a centralised, 'optimised' emergency plan that is imposed top down might not be practicable.

The results of the consultation were used to choose the appropriate modelling techniques for implementing the evacuation model. The outcomes from the consultation also informed the development of evacuation scenarios aiming to describe the current situation in Padang and to assess possible tsunami risk reduction interventions.

\section{Review of current emergency evacuation procedures and previous events}

Padang was subjected to several earthquakes in the last few years. In 2007, a M8.4 earthquake, followed by a M7.9 earthquake $12 \mathrm{~h}$ later, caused the destruction of hundreds of buildings (World Health Organisation 2007). Another event of M7.6, known as the '2009 Padang earthquake', caused 1,195 deaths (USGS 2010). On 11 April 2012, two strike-slip earthquakes of M8.6 and M8.2 occurred within the Indo-Australian plate, about 100 and $200 \mathrm{~km}$ south-west from the Sunda megathrust, respectively (USGS 2012). The 2009 earthquake did not generate a significant tsunami, but the population started evacuating after the earthquake. Witnesses reported that the evacuation was obstructed by heavy traffic and the roads were congested for hours (USGS 2010; Brooks 2010; Hoppe and Mahadiko 2010). The 2012 earthquake did not occur on the megathrust and also did not generate a large tsunami, but was distinctively felt by the population of Sumatra. A representative from Kogami reported that in the city of Padang, the tsunami warning was disseminated $30 \mathrm{~min}$ after the earthquake through sirens. This occurred despite the Tsunami Warning Centre in Jakarta providing a correct 'all clear' message minutes from the earthquake. Also, the sound of sirens was in some cases misinterpreted by the population. Once the evacuation initiated, the roads became gridlocked by traffic jams, trapping people for several hours (Andriani 2012). Both 2009 and 2012 events showed the same pattern regarding vehicular evacuation. The response to the 2012 event shows that improvements have been made in terms of warning systems, issues in the decision-making chain, and communication still prevented a timely dissemination of the warning. The communities are thus still unprepared, partly 
unaware of the meaning of the warning messages, and not fully embracing the evacuation practices suggested by BPBD and local NGOs.

The current emergency plan of the city, prepared and shared by BPBD, does not specifically include suggested evacuation routes. The current evacuation map (available at GITEWS 2010), only suggests moving outside of the potential inundation area, and does not suggest specific routes nor report evacuation times. According to this map, the maximum distance to cover is about $5 \mathrm{~km}$ in a straight line, thus about $7-8 \mathrm{~km}$ on the road. The vehicle evacuation has proven to be ineffective due to traffic jams; on the other hand, most of the people cannot cover this distance by foot within $30 \mathrm{~min}$. Thus, the current evacuation procedure proposes a strategy that cannot be possibly implemented within $30 \mathrm{~min}$, even if the tsunami warning system works perfectly.

\section{Specific research objectives and modelling approach}

The results from the literature review, the consultation and the analysis of previous events defined the baseline for the research questions and therefore the model's specifications. The main objectives for the analysis were set as follows:

- Assess the consequences of evacuating by vehicles, in comparison with the pedestrian evacuation.

- Extend the analysis to the whole city, including the northern part.

- Provide realistic evacuation times to quantify the actual difference between the time needed to evacuate and the time available before the tsunami's arrival.

- Assess the actual benefits of interventions such as vertical evacuation shelters, to provide a strong case to support the implementation of risk reduction measures.

To fulfil these objectives, we first developed an evacuation model that would realistically represent the local traffic patterns. The resulting model can represent either vehicular or pedestrian traffic. The model is also able to simulate mixed pedestrian and vehicle traffic. The algorithms governing the hybrid traffic have not yet been validated (Di Mauro et al. 2013). Because of this, here we refer to the pedestrian and vehicular evacuation modules as separate entities.

The programming code was written in Java, using the IDE Eclipse (The Eclipse Foundation 2012) and the MASON library core for agent-based modelling (Luke et al. 2005).

\subsection{Simulation of the vehicular traffic}

Indonesian cities, like in some other Southeast Asian countries, present specific traffic patterns that differ from those of 'western' cities. Southeast Asian cities present a very specific traffic composition, including a high rate of motorbikes and smaller vehicles (e.g. see Hoang et al. 2010). The assumptions made by most of the commonly used traffic models, such as lane divisions and queuing patterns, are not applicable to many cities in Southeast Asia. This was confirmed by the specific traffic patterns observed during the recent mass evacuations following the earthquakes on the 30 September 2009 (Brooks 2010; Hoppe and Mahadiko 2010) and the most recent one on the 11 April 2012 (Andriani 2012).

The other challenge in defining the specifications for a vehicular traffic model for Padang is the high number of vehicles to be represented. This requirement might suggest the implementation of a macro-scale model. This type of model requires modelling 
explicitly the macroscopic traffic variables (such as flow rate, vehicle density and average vehicle speed); therefore, the traffic is represented as a continuous flow, with the conservation and momentum equations being solved numerically. The traffic 'particles' (vehicles or pedestrians) are not modelled explicitly. On the other hand, for Padang, there is a need for modelling traffic conditions where the roads are stressed to their full capacity, as well as allowing flexibility to model individuals' behaviour. Macro-models are characterised by the instability of the governing equations in full-capacity traffic conditions (Kerner 2009). This and the desired ability of the model to explore the different behaviour of the evacuees favour a micro-approach. Micro-models represent the vehicles as individual 'particles', assigning them some rules to regulate their mutual interaction, which represent individual behaviours. The global traffic parameters result from these individual interactions, and therefore, they are 'observed' instead of being explicitly 'modelled' (Kerner 2009). Meso-models lay somewhere between the two, usually by modelling the traffic 'particles' individually but simplifying their interactions so that they are assigned macroscopic behaviours in some part of the network (e.g. at intersections). We therefore chose a meso-scale approach, in order to be able to model the large number of vehicles/ pedestrians in Padang and, at the same time, be consistent with the actual volume of traffic.

We developed a model that represents the vehicles as individual entities (agents) that occupy a physical space in the model domain, and they can assume individuals' behaviour. The model in this sense is 'agent-based'. The traffic at the road junctions (nodes), including the 'start' and 'end' points, is modelled with a micro-scale approach, by assigning a maximum capacity to the junction (traffic volume per unit of time) according to which each vehicle (or pedestrian) can or cannot enter the junction. Along the roads, the traffic is modelled following a macro-scale approach, the flow-speed relationship, as well as the maximum capacity of the roads, which are calculated from the Indonesian Highway Capacity Manual (Departemen Pekerjaan Umum 1997). These equations are only applicable until the maximum capacity of the roads is reached; therefore, the inflow and outflow in the roads have to be modelled following a micro-scale approach: when the maximum capacity is reached, the vehicle cannot enter the road, so it will be forced to wait on the upstream junction. Similarly, empirical fundamental diagrams for the intersections (also from the Indonesian Highway Capacity Manual (Departemen Pekerjaan Umum 1997)) are used to model the relationships between the capacity and actual inflow, which determines the effective inflow and waiting time at the intersections. If the vehicle cannot enter the intersection, it spills back to the road, contributing to the current capacity of the road. The continuity equation is in respect of both the road-junction interfaces and the junction-road interfaces; the flow of vehicles exiting a junction (road) will equal the flow entering the downstream junction (road) plus the vehicles waiting at the node (road). The nodes also have a storage capacity determined from the Indonesian Highway Capacity Manual. The model has a way in handling the spillbacks: in a macro-model, to enable the continuity equation to converge, the spillbacks are managed by performing iterations at each time step, to allow the full traffic 'spillback' to be resolved in one time step. In reality, the spillback does not occur instantaneously, and the junctions have a certain storage capacity, which is also proportional to the model's time step (Gordon 1969; Kerner 2009). The spillback can be assumed to occur within one time step, meaning that the effect of the spillback is felt by the network in the subsequent time step. This is possible assuming that the volume of traffic that spill back in one time step is lower than the maximum traffic volume per time step (i.e. the maximum capacity of the road or the node). To assume that, we also need to respect the condition that the storage capacity of the nodes is at least equal to the maximum traffic volume per time step. These conditions are required to be satisfied 
everywhere in the road network except for the source nodes (where the vehicles/pedestrians start) and the arrival nodes, as these nodes are assumed to be able to store a larger number of vehicles. However, if the arrival node is set to have limited capacity, the model does not allow the vehicles to enter if the node maximum capacity is reached. The arrival nodes also have a specified ingress rate, which regulates the entrance rate to the node. For the vehicular traffic, the arrival nodes are defined to be the high ground, modelled as areas with very high storage capacity in which the people can station with their vehicles.

The origin-destination matrix is calculated by assigning each vehicle to the nearest arrival node, calculated using the modified Dijkstra's algorithm (Lee 2006), using the road lengths as weight for the optimisation. This route choice is then 'personalised' for each vehicle, which allows further developments of the model to take into account individual behaviours in the choice of the route.

\subsection{Simulation of the pedestrian traffic}

We adopted a similar approach to the one followed for vehicular traffic to model the pedestrian traffic. A maximum capacity is assigned to the junction according to whether each person can or cannot enter the junction. The junctions are treated as bottlenecks, whose capacity is determined according to Hoogendoorn and Daamen (2005). This capacity represents the relationship between the capacity and actual inflow which determines the effective inflow and waiting time at the intersections. If the pedestrian cannot enter the junction, it will be forced to wait on the upstream road, contributing to the current capacity of the road. Similarly to the vehicular traffic model, the pedestrians are modelled following a macro-modelling approach to represent their movements along each road; thus, all the people in the road link are assumed to have the same average speed, calculated using Weidman's diagram for pedestrian along the links (Weidman 1993).

The approach for modelling the spillback junction-road and road-junction is same as the one adopted for the vehicular traffic model. The difference lies in the representation of the arrival nodes, which for the pedestrians can also consist in vertical evacuation structures. Depending on the type of structure modelled (evacuation hill, building, pedestrian bridge, etc.), the arrival node has a specific ingress rate and a minimum time that the person has to spend to reach the top of the structure. Until this minimum time is not passed, the person will be made to artificially wait at the bottom of the structure, contributing to the congestion of the ingress road. This represents the actual congestions that occur entering in confined structures such as buildings (Kretz et al. 2008) and needs to be carefully accounted in this type of model. The vertical evacuation structures were also assigned a limited maximum capacity, depending on the type of structure. If the evacuees reach the shelter and they find that it has reached its maximum capacity, they turn back and head for the next closest shelter.

The origin-destination matrix is also calculated following the modified Dijkstra's algorithm (Lee 2006). This is re-calculated if the pedestrian arrives at a full evacuation shelter, so that they get assigned to the next closest shelter, chosen from those that the pedestrian has not visited so far.

\section{Implementation}

The inputs of the model that we developed include the road network, made up of links and nodes. To each node, the user needs to specify the $\mathrm{x}$ and $\mathrm{y}$ coordinates of the node, a unique 
id, the number of people starting from the node, the node type (intersection connecting a main road or secondary intersection) and the intersection width. The links require the specification of the $\mathrm{x}$ and $\mathrm{y}$ coordinates of their starting and end points, a unique id, the width, the length and the free flow speed for pedestrians and vehicles. The characteristics of the road network were obtained from OpenStreetMap (www.openstreetmap.org) and manually cross-checked against the satellite images provided by Google Satellite (maps.google.com.sg), through the OpenLayer plugin of QuantumGIS (www.qgis.org). The modelled network included 1,343 nodes and 2,330 links. The layout of the modelled area is shown in Fig. 1.

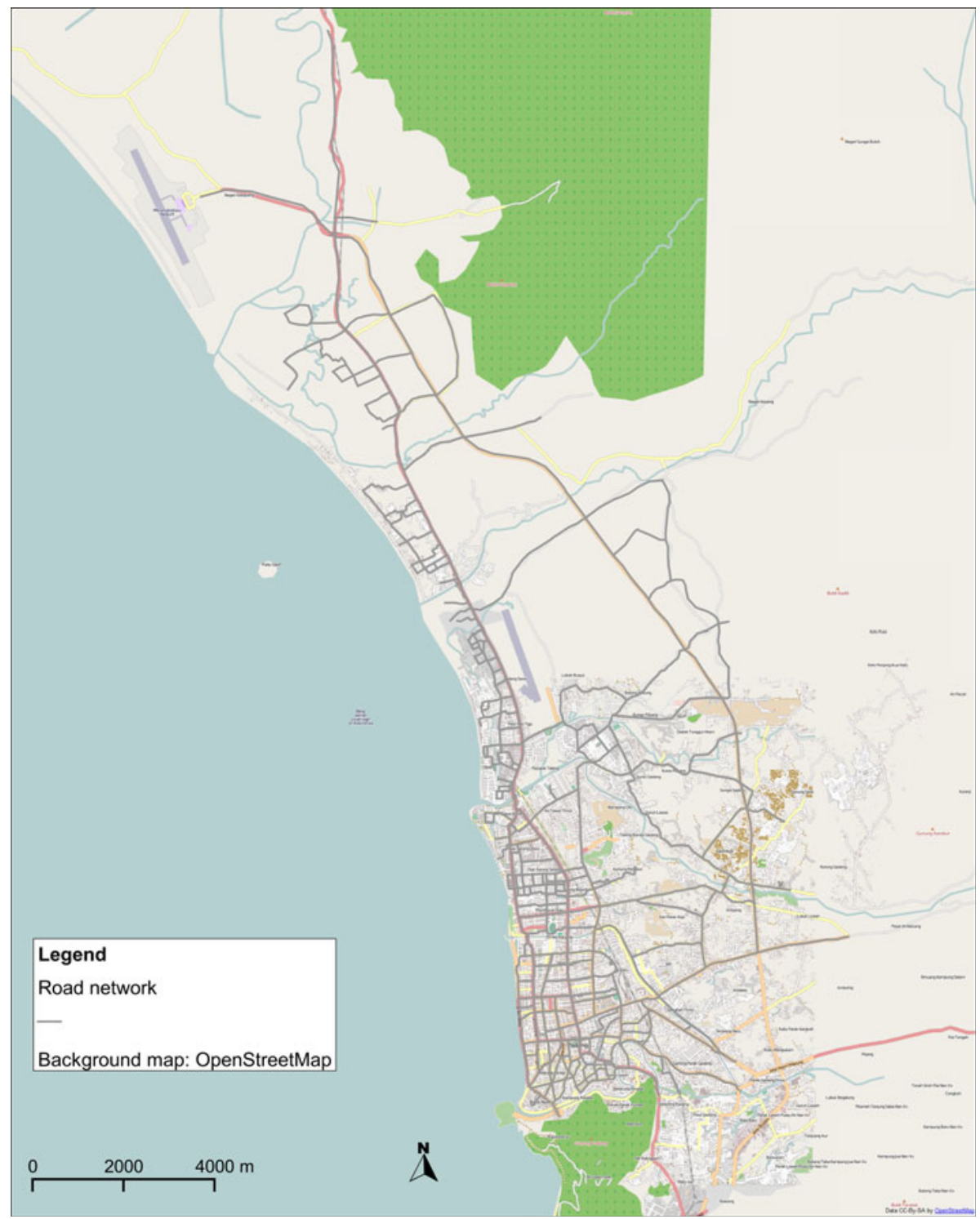

Fig. 1 Modelled area 
The capacities of the roads and intersections for vehicles are calculated following the Indonesian Highway Capacity Manual, in the section on urban roads (Departemen Pekerjaan Umum 1997). For pedestrians, these were calculated following Hoogendoorn and Daamen (2005). The free flow speeds for pedestrians and vehicles were calculated, respectively, from Departemen Pekerjaan Umum (1997) and Lammel et al. (2010), who adapted the value from Weidman (1993). The parameters and their sources are specified in Table 2. The model also requires the user to define the physical space occupied by the vehicles, the motorbikes and the people, which values were taken from Chandra and Kumar (2003) and Korhonen et al. (2010).

The population distribution was assumed following the 2005 census of Kota Padang (BPS Kota Padang 2005) and integrated with a density map produced by MapAction (2009) to include the population in the northern part of the city, which is outside of Kota Padang, thus not included in BPS Kota Padang (2005). According to these data, about 334,500 people reside in the urban settlement. Administratively, this includes part of the Kecamatan (subdistrict) of Kototangah, belonging to the Kabupaten (district) of Padang Pariaman, and the Kecamatan of Nanggalo, Padang Utara, Padang Barat, part of Padan Timur and Kurangi, belonging to the Kabupaten of Kota Padang (www.padang.go.id).

Two 'baseline' scenarios were modelled. In the first scenario, the population is assumed to evacuate by cars and motorbikes to high ground. The model does not explicitly include any inundation scenario. Due to the uncertainties in the available literature on possible inundation scenarios for Padang, we should not overinterpret these results in defining the 'safe places'. We therefore define the 'high ground' as the areas in which the topography is higher than $30 \mathrm{~m}$, which is a $20 \%$ higher elevation than is reported in the most conservative inundation study (Gayer et al. 2010). These locations are well outside the potential inundation area presented in the 'official' tsunami inundation map (Cedillos 2011). An average of two people per motorbike and four people per car are assumed (Chandra and Kumar 2003), and a distribution of $80 \%$ of motorbikes and $20 \%$ of cars, which was roughly assessed by analysing the video of the evacuation that occurred on 11 April 2012 (Andriani 2012). Therefore, in the baseline scenario, 117,075 motorbikes and 33,450 vehicles are modelled. In the second scenario, the people are assumed to be evacuating by foot. These two baseline scenarios were chosen to investigate whether the current evacuation mode (vehicles) constitutes a worst-case scenario with respect to the pedestrian evacuation mode, which is the only one considered in literature. Another set of scenarios

Table 2 Parameters used in the model and their sources

\begin{tabular}{|c|c|}
\hline Parameter description & Value and/or source \\
\hline Road capacity—vehicles & $\begin{array}{l}\text { Function of road type and width } \\
\text { (Departemen Pekerjaan Umum 1997) }\end{array}$ \\
\hline Intersection capacity—vehicles & $\begin{array}{l}\text { Function of intersection type and width } \\
\text { (Departemen Pekerjaan Umum 1997) }\end{array}$ \\
\hline Road capacity_pedestrians & Function of road width (Departemen Pekerjaan Umum 1997) \\
\hline Intersection capacity-pedestrians & Function of intersection width (Hoogendoorn and Daamen 2005) \\
\hline Vehicle size (cars and motorbikes) & (Chandra and Kumar 2003) \\
\hline Person size & (Korhonen et al. 2010) \\
\hline Free flow speed-vehicles & (Departemen Pekerjaan Umum 1997) \\
\hline Free flow speed-pedestrians & (Lammel et al. 2010) \\
\hline Time step & $60 \mathrm{~s}$ \\
\hline
\end{tabular}


was implemented to assess possible disaster risk reduction options. These were developed in collaboration with the local actors working on risk reduction and emergency management in Padang.

The work of Lammel et al. (2010) showed that, in the particular case of Padang, the number of people from the night-time and day-time scenarios do not differ substantially. Hence, we assumed here that all the people are at home before the evacuation (night-time scenario). In terms of departure curve, we decided not to include the official warning in the model, due to the observed delays in which this was disseminated in the past. Within the current operational state of the warning dissemination, the population will have at most a few minutes between receiving the warning and the arrival of the tsunami. In fact, the population should not wait for the warning, but start evacuating immediately after the earthquake. Even if they evacuate immediately after the earthquake, the people are likely to hesitate in evacuating directly, possibly to gather information and reach their family, etc. (e.g. Drabek 1986). Due to the uncertainly in forecasting the behaviour of the population, we assume that people evacuate directly after the earthquake and go straight towards the high ground or the closer vertical evacuation shelter (when available), acknowledging that this scenario in reality is likely to underestimate the evacuation time.

\section{Results}

\subsection{Vehicular evacuation}

The first modelled scenario assumes that people evacuate by vehicles. The results show that, after $20 \mathrm{~min}$, the vehicles trying to reach the major arterial road crossing the city from north to south (Jalan Bypass) and the area of Lubuk Minturun are one of the main sources of congestion for northern part of the city (Figs. 1 and 2). Jalan Bypass is located about $4 \mathrm{~km}$ inland, while the area of Lubuk Minturun is $\sim 6 \mathrm{~km}$ away from the shoreline. People located in the area around the international airport (north of Jalan Simpang Kalumpang) evacuate within 20-30 min, except for some traffic still trying to reach the small hill of Bukit Cubadak; this is cleared within $40 \mathrm{~min}$. The people trying to evacuate to the high ground in Lubuk Miturun have to pass either side of the old military airport (the Tabing airport, now unused). These evacuees are stuck in traffic jams in the roads adjacent to the old airport (Jalan Lubuk Minirun and Pasar Nan Tigo, close to the Padang University) as all the roads are gridlocked. The last vehicles able to leave the area of Pasar Nan Tigo can do so only after $\sim 35 \mathrm{~h}$. In the southern part of the city, the congestion is mainly due to the vehicles trying to reach the area of the Andalas University campus ( $\sim 8 \mathrm{~km}$ inland), especially along Jalan Radeh Saleh and Jalan Andalas. The roads closer (and parallel) to the coast also become congested due to people trying to reach the hill located in the southernmost part of the city. The congestion patterns obtained from the simulation were similarly observed during the evacuation of the 11 April 2012 (Andriani 2012).

In this scenario, only 49,563 people over the total 334,500 (14.8\%) manage to evacuate to the high ground after $20 \mathrm{~min}$ (Fig. 3). After $30 \mathrm{~min}, 63,873$ people evacuate $(19.1 \%$ of the total population), and after $1 \mathrm{~h}$ only 91,752 people (27.4\% of the evacuees) reach the high ground, while the $72.6 \%$ of the population is still on the road. The evacuation pattern presents a high variance, with average evacuation time of $7.38 \mathrm{~h}$, a maximum time of $33.97 \mathrm{~h}$ and a standard deviation of $108.3 \%$ (7.99 h). The values of arrival times are in fact spread, as shown in Fig. 5a. 


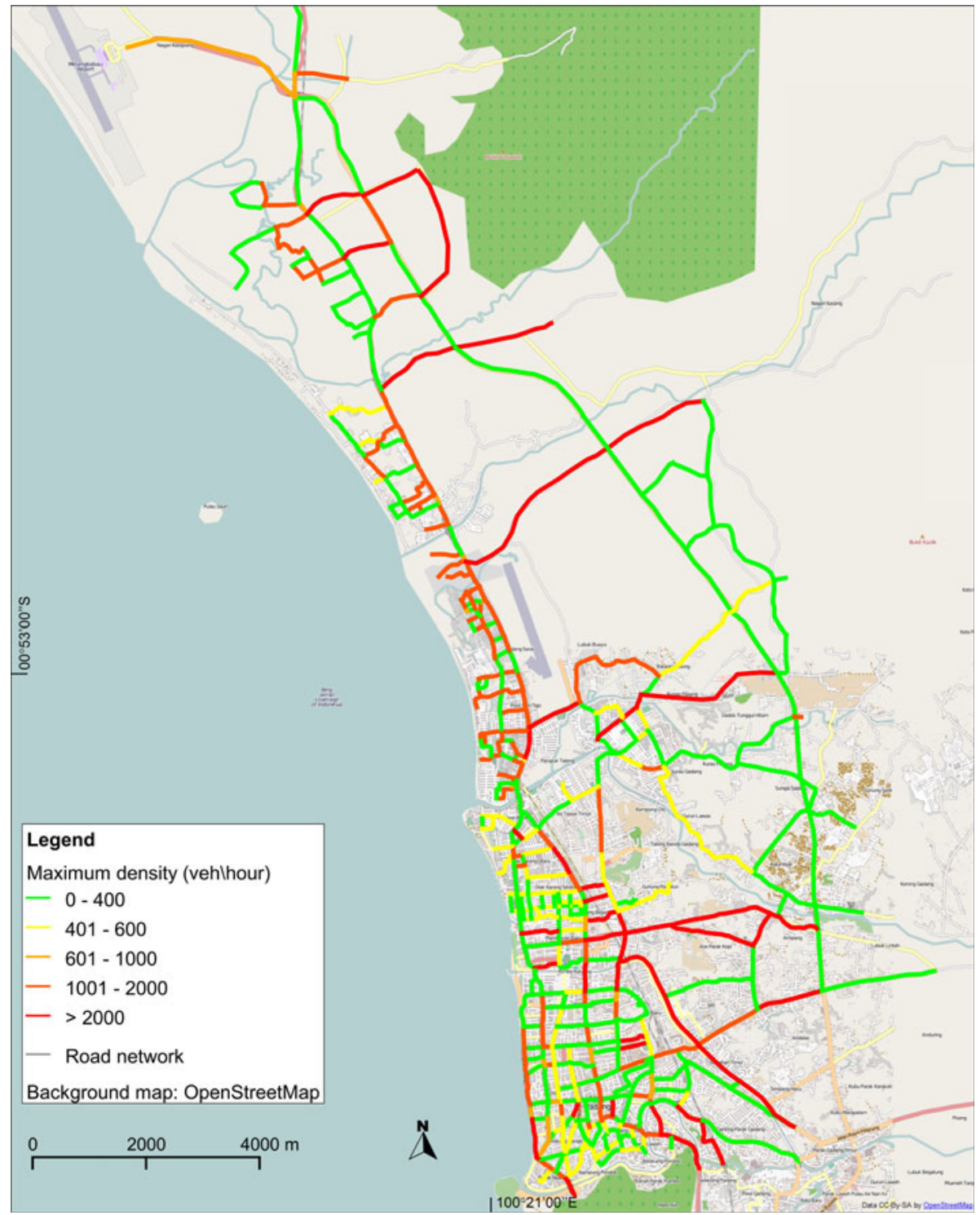

Fig. 2 Maximum density of vehicles in the roads (in vehicle/h) calculated in the simulation

\subsection{Pedestrian evacuation}

The second scenario assumes that all the population evacuate by foot. In the southern part of the city, Andalas University campus (Jalan Andalas) is cleared after $48 \mathrm{~min}$; the roads towards the hill of Gunung Pangilung, 3.5 inland and those leading to Jalan Bypass are congested but cleared after $46 \mathrm{~min}$; the roads leading to the area of Indarung constitute the last part of the network to be cleared after $3 \mathrm{~h}$, together with the area of Gunung Pangilun (Figs. 1 and 4). During the first $40 \mathrm{~min}$, the pedestrian evacuation in the northernmost part 


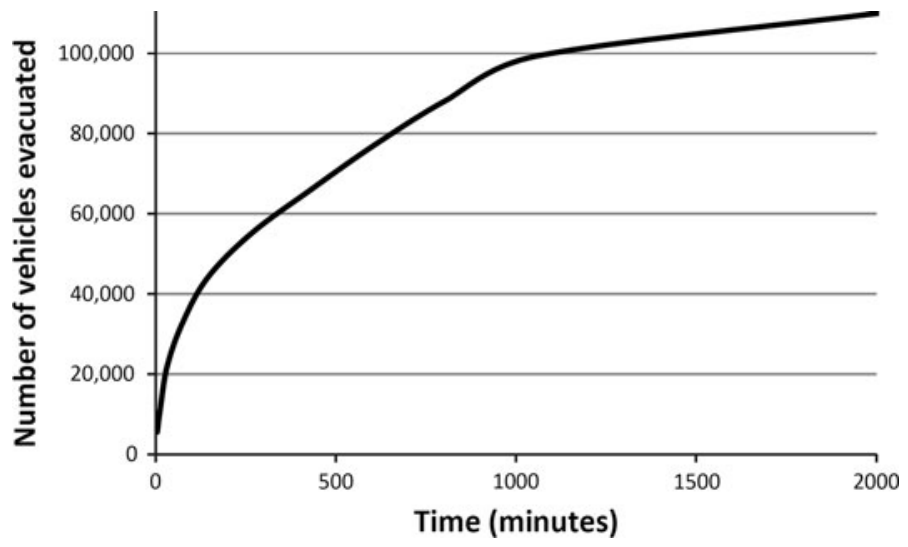

Fig. 3 Evacuation curve showing the timeline of the cumulative number of vehicles evacuated

of the city (north of Jalan Simpang Kalumpang) is slightly slower than the evacuation by vehicles (Figs. 1 and 2). People coming from the coastal area encounter high density of traffic along the main arterial road called Jalan Adinegoro, which runs parallel to the coastline about $800 \mathrm{~m}$ from the shore. People evacuating to the hill of Bukit Cubadak (located about $5 \mathrm{~km}$ from the shoreline) through the northward road of Jalan Simpang Kalumpang are able to do so within 60 min. People trying to reach the area of Lubuk Minturung encounter congestions in both sides of the old airport, as Jalan Lubuk Minirun is cleared only after about $1.5 \mathrm{~h}$, while Jalan Maransi is congested until $2.8 \mathrm{~h}$ from the start of the evacuation. The main difference with the vehicle evacuation scenario is that the coastal area of Pasar Nan Tigo (close to Padang University) is not gridlocked and the people are able to reach at least the area of the old airport within $40 \mathrm{~min}$.

The results from this scenario show that after $20 \mathrm{~min}, 51,739$ people (15.5\% of the population) manage to evacuate to the high ground. After $30 \mathrm{~min}, 86,408$ people evacuate. After $1 \mathrm{~h}, 158,096$ people, constituting the $47.3 \%$ of the population, evacuate to high ground, against the $27.4 \%$ that manage to evacuate by vehicles in the previous scenario. The maximum evacuation time is $3 \mathrm{~h}$, while the average evacuation time is $1.2 \mathrm{~h}$, with a standard deviation of $66.6 \%$ (47.9 min). The distribution of the arrival times is in fact less dispersed than in the case of the vehicular evacuation (Fig. 5b).

The evacuation curve is shown in Fig. 6, together with the evacuation curve obtained by Lammel et al. (2010) for the base (not optimised) scenario. The calculated evacuation rate is lower than the one reported by Lammel et al. (2010). This is likely due to the introduction of the delays at the intersections. However, the results of the two models are analogous, despite differences in equations, computational methods and the input data (in particular, those regarding the population distribution and road network).

\subsection{Assessment of interventions for enhancing the evacuation rate}

Different scenarios assessing possible tsunami risk reduction options were set up following the consultation with the local actors. The northern and southern parts of the city present distinct characteristics in terms of population density, total number of people and topography. For that, the envisaged solutions for the two parts of the city are also different. These two parts were thus analysed and modelled separately. We consider the Kuranji river to be the separation between the northern and the southern areas. 


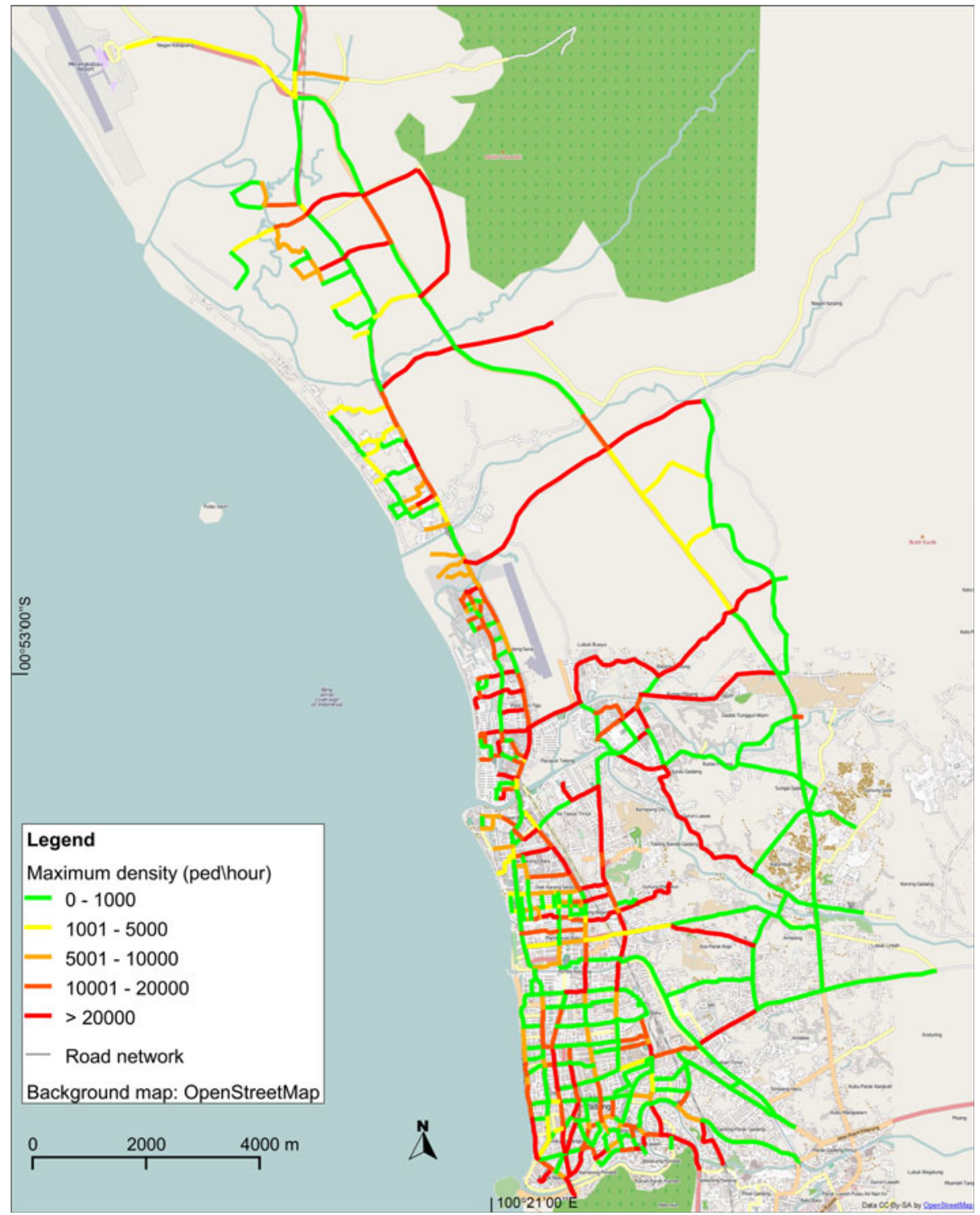

Fig. 4 Maximum density of people in the roads (in pedestrians/h) generated from the simulation

\subsubsection{Analysis of evacuation options for the northern part of the city}

The baseline scenarios from which we start appraising the interventions are the vehicle-only and pedestrian-only scenarios. The northern part of the city is considered separately here. For the vehicle-only scenario, the model shows a great dispersion of the arrival times, with high standard deviation $(10.8 \mathrm{~h}, 111.8 \%)$, as shown in Fig. 8a. The average evacuation time is $9.7 \mathrm{~h}$, while the maximum is $33.97 \mathrm{~h}$. A total of 25,767 people can evacuate after $30 \mathrm{~min}$, which corresponds to the $19.8 \%$ of the population located in the northern part of the city. 
(a)

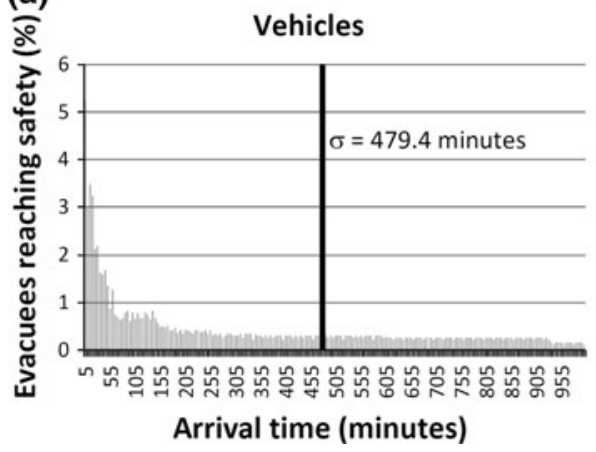

(b)

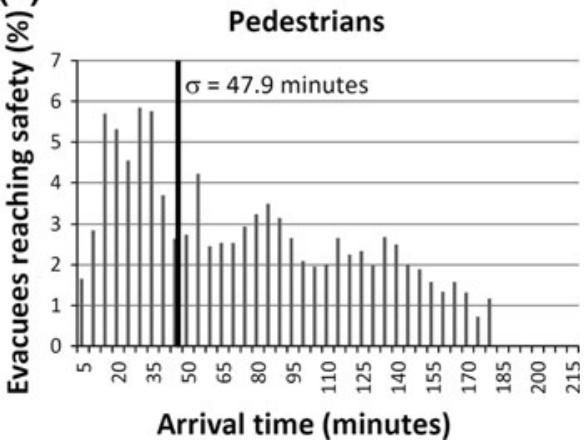

Fig. 5 Distribution of arrival times for the vehicles-only evacuation (a) and pedestrians-only evacuation (b) scenarios

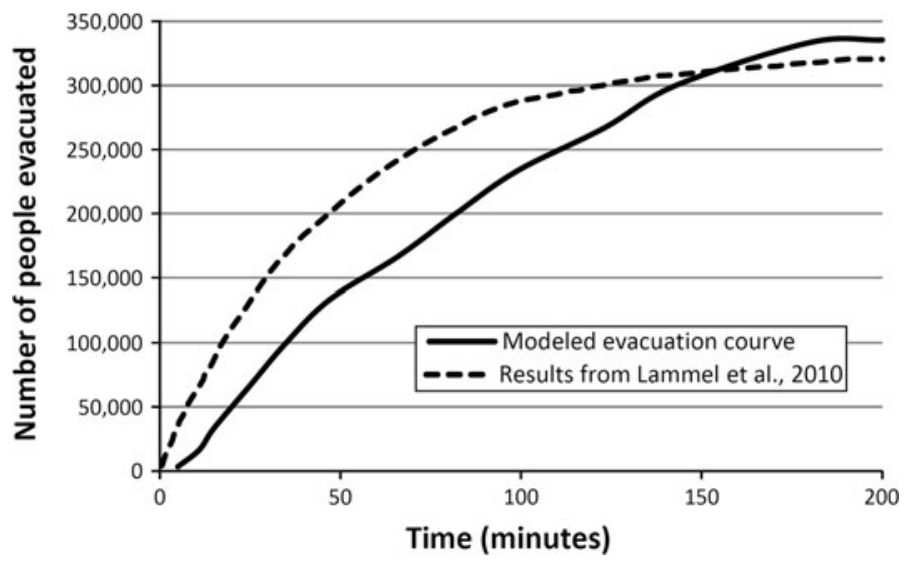

Fig. 6 Modelled evacuation curve and comparison with the results presented by Lammel et al. (2010)

The scenario that assumes only pedestrian evacuation results in an average evacuation time of $1.38 \mathrm{~h}$, and a standard deviation of $49.7 \mathrm{~min}(60.2 \%)$, which means a less disperse distribution of the evacuation times (Fig. 8b). The maximum calculated evacuation time is $3 \mathrm{~h}$. The $17.6 \%$ of the population of the northern part of Padang $(21,825$ people $)$ reaches safety after $30 \mathrm{~min}$.

The first analysis of interventions for the northern part of the city aims to appraise the option suggested by the local NGO Kogami. Considering the reservations that the population have shown in the past regarding evacuating to a built structure after a potential M8.9 earthquake, building wider roads seems to be an option that can be more easily endorsed by the evacuees. For that, we increased the road capacity by doubling the width of the roads that were heavily congested in the previous scenarios (Jalan Adinegoro, Jalan Lubuk Miturung, Jalan Maransi and Jalan Hamka). We analysed both the vehicular evacuation (scenario 1) and the pedestrian evacuation (scenario 2). In scenario 1,43,425 people $(33.4 \%)$ can reach safety after $30 \mathrm{~min}$. However, the average evacuation time is $7.2 \mathrm{~h}$, with peaks of $25.47 \mathrm{~h}$ and a standard deviation of $8.2 \mathrm{~h}(113.9 \%)$, as shown in Fig. 8c. In scenario 2, people are assumed to evacuate by foot through the widened roads. 
The results of this scenario show an average evacuation time of $1.13 \mathrm{~h}$, with a maximum of $2.33 \mathrm{~h}$ and a standard deviation of $54 \%$ (36.8 min). A total of 22,309 people can evacuate within the first $30 \mathrm{~min}$, which corresponds to the $18 \%$ of the population in North Padang.

GeoHazards International (GHI) is an international NGO whose aim is to reduce earthquake risk, by 'helping communities move from knowledge to action' (www.geohaz. org). GHI carried on a study that commenced in 2009, involving experts from Stanford University and in consultation with local partners. This study concluded that one of the most suitable interventions to reduce tsunami risk in Padang consists in building highcapacity, high-resilience vertical evacuation shelters in the form of Tsunami Evacuation Parks. The Tsunami Evacuation Parks are man-made hills that are engineered so that their height and slope ensure the protection against a possible tsunami (www.geohaz.org). This type of intervention is potentially implementable in the northern part of the city (north of the Kuranji river) where the size of the population $(124,118$ people) and the average density $\left(2,489 \mathrm{in} / \mathrm{Km}^{2}\right)$ are lower than those in the southern part. In the northern part, it is also possible to identify some potential locations for hosting such structures without the need of demolishing existing buildings, as it would be needed in the southern part (Cedillos 2011). GeoHazards International is currently planning to build one of such structures in the Padang University campus (Jalan Hamka), whose capacity would be of approximately 7,600 people. The NGO also recognised that the area of the old airport is particularly suitable for hosting other evacuation parks (Cedillos 2011).

Scenario 3 included the two structures that are most likely to be built within the next couple of years, thanks to the potential availability of funding. These would be an evacuation park in the Padang University campus (structure A, Fig. 7) and a structure in the area of the old airport that could host about 7,600 people (structure B, Fig. 7). If such structures are included in the model, 35,389 people can reach safety within $30 \mathrm{~min}$, of which 15,174 to the shelters, the rest to high ground. This corresponds to $27.8 \%$ of the population. The average evacuation time is $1.76 \mathrm{~h}$, with a recorded maximum evacuation time of $4.32 \mathrm{~h}$, with a standard deviation of $65.5 \mathrm{~min}(66.1 \%)$. It is interesting to notice that the distribution of the arrival times has bi-modal characteristics (Fig. 8d), as the lower arrival times correspond to the people reaching the shelters until these are full. The second distribution includes the people that try to reach the Padang University shelter at first. These evacuees find the shelter already full, thus have to move towards the next closer
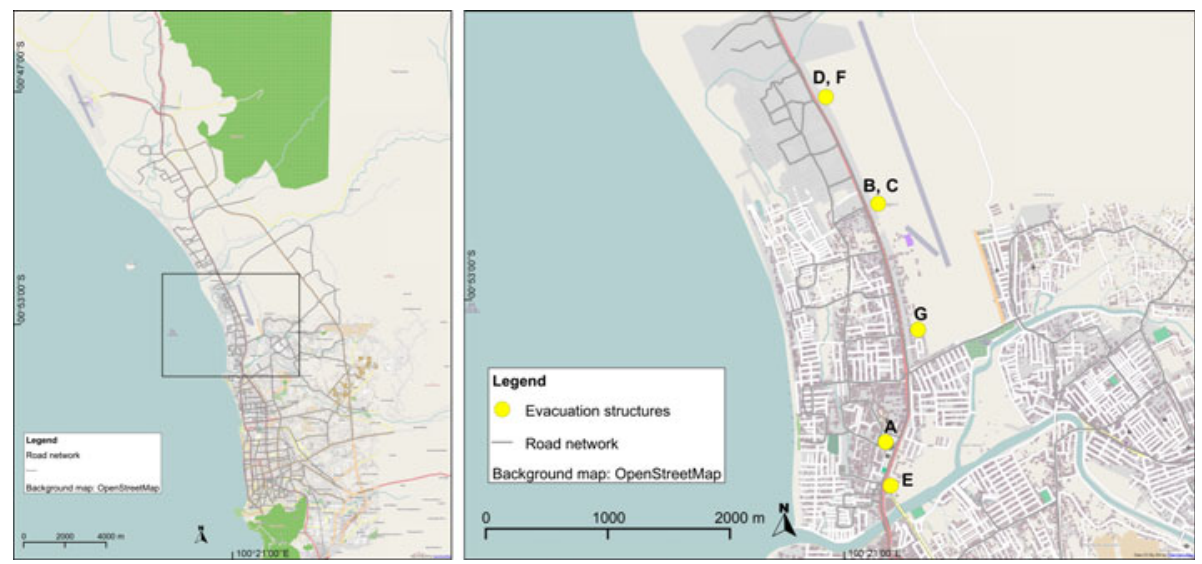

Fig. 7 Analysed potential locations of the evacuation hills for the northern part of Padang 
(a)

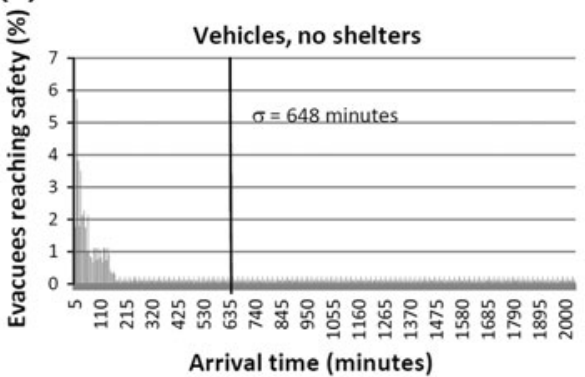

(c)

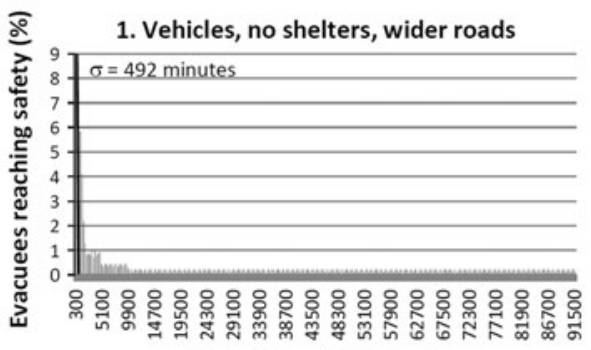

Arrival time (minutes)

(e)

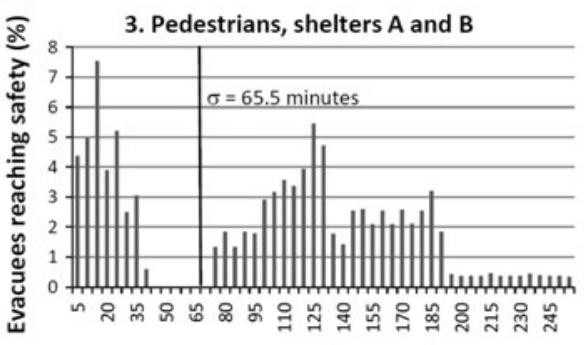

Arrival time (minutes)

(f)

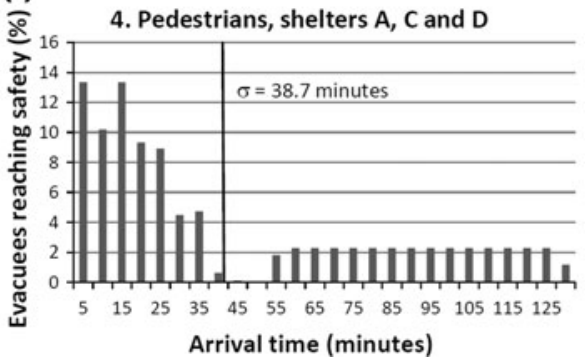

(b)

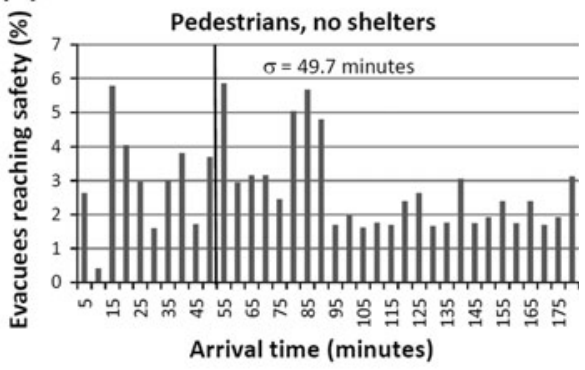

(d)

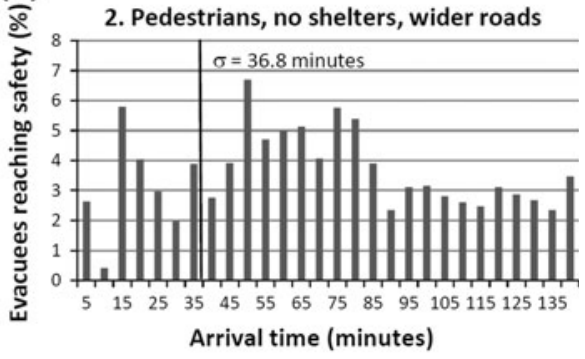

(g)

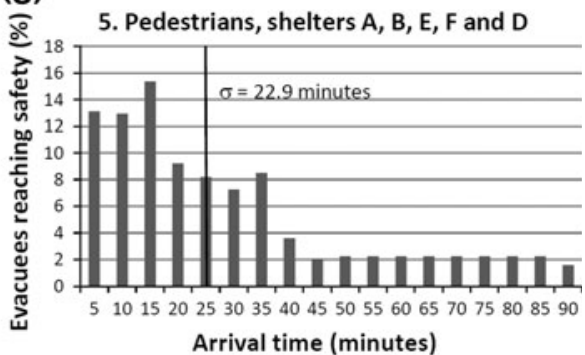

Fig. 8 Distribution of the arrival times for the evacuation scenarios analysed for the northern part of Padang. The black lines indicate the values of the standard deviation of the arrival time (min)

evacuation shelter. This implies that they have to cover a larger distance, spending time on the heavily congested roads leading to (and from) the first shelter, hence the second peak of the distribution. 
The vertical evacuation structures, to be fully effective, should have a total capacity comparable to the number of inhabitants of the northern part of the city. The area available at the Padang University campus does not allow for the building of a structure larger than the structure already assumed in scenario 3 (structure A, Fig. 7). On the other hand, the old airport has the potential for hosting much larger structures. For that, we considered the structure in the Padang University campus (structure A, Fig. 7) and two structures in the area of the old airport with capacities of 120,000 (structure C, Fig. 7) and 92,000 (structure D, Fig. 7) people (scenario 4). The capacity of these hypothetical structures was calculated according to the space available and assigning one person per square metre (FEMA 2008). According to this scenario, 73,987 people can reach safety within $30 \mathrm{~min}$, corresponding to $59.6 \%$ of the population. The average evacuation time is $40.8 \mathrm{~min}$, while the maximum evacuation time is $2.13 \mathrm{~h}$, with a standard deviation of $94.8 \%$ (38.7 $\mathrm{min})$. The distribution of the arrival times is shown in Fig. 8e. Also, here it is possible to appreciate the separation between the people who reach the evacuation shelter directly and those who reach a full shelter first, thus have to re-route to another one. This scenario also showed that the two structures are over-dimensioned as only 30,429 and 62,110 people reach, respectively, the structure $\mathrm{C}$ and the structure D (Fig. 7).

As mentioned above, the structures A and B (Fig. 7) are likely to be implemented in the short term. For that, we considered a scenario assuming such structures have been built, to analyse which additional structures would be needed to enable more people to reach safety on time. The results from the previous scenarios show that the southernmost part of the modelled area, the area located west of Jalan Parman, is subjected to congestion due to the density of evacuees and the limited capacity of the roads. The structure A is not able to contain all the people evacuating the area $(\sim 46,000$ people), and therefore, another structure is assumed in the area on the immediate east of Basko GrandMall. This area can only host a structure with capacity of 7,000 people (structure E, Fig. 7). The structure B is already in the area of the old airport, but its planned capacity is limited to 7,000 people. We therefore assumed two further structures (structure F and structure G, Fig. 7) in the same area, which can host 60,000 people, each to provide for the extra capacity needed. The results of the scenario including the structures A, B, E, F and G (scenario 5) show that 82,774 people are able to reach either structure within $30 \mathrm{~min}$, which corresponds to $66.7 \%$ of the population. The average evacuation time is of $27 \mathrm{~min}$, with a maximum of $1.47 \mathrm{~h}$ and a standard deviation of $22.9 \mathrm{~min}(83.8 \%)$. Figure $8 \mathrm{~g}$ shows the distribution of the arrival times. Both the structure F and the structure G (Fig. 7) were over-dimensioned as they finally hosted, respectively, 32,626 and 46,018 despite their capacity of 60,000 people. The structures A, B and E (Fig. 7) are used to their full capacities.

Table 3 contains the summary of the results obtained for the northern part of Padang.

\subsubsection{Analysis of evacuation options for the southern part of the city}

The Kuranji River bends southwards, separating the coastal area from the high ground to the East. Two other main waterways cross the southern part of Padang. The Arau river separates the southernmost part with the hill of Gunung Padang. The Banjir Kanal (channel) divides the area into two and bends southwards parallel to Jalan Bakti 2 (Fig. 1), separating the western coastal part from the high ground to the East. Therefore, the only way of reaching the high ground from most of the southern part of the city is to cross these waterways by means of one of the fourteen existing bridges, provided that they can withstand the earthquake ground shaking. The population density of the southern part of the city is on average $6,267 \mathrm{in} / \mathrm{Km}^{2}$, and the urban layout does not present any area 


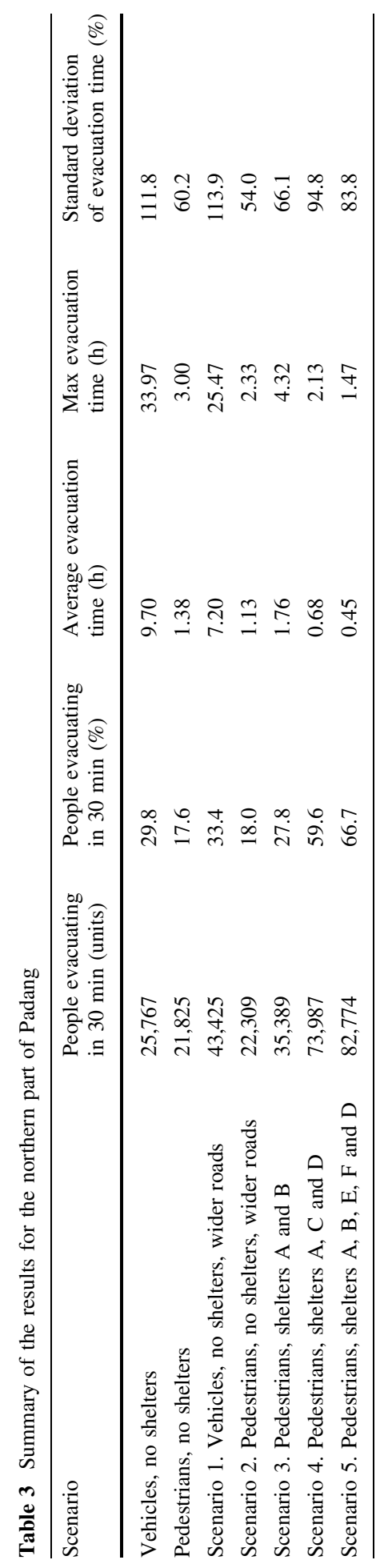


available to host large evacuation structures such as the Tsunami Parks. The total population is about 210,421 people.

The scenario analysing the vehicular evacuation for the southern part of the city resulted in an average evacuation time of $6.01 \mathrm{~h}$, with a standard deviation of $86.6 \%(5.2 \mathrm{~h}$, Fig. 10a). The maximum evacuation time is $17.81 \mathrm{~h}$. A total of 38,106 people $(18.3 \%$ of the population in the southern part) reach safety after $30 \mathrm{~min}$.

The analysis of the pedestrian evacuation results in 64,582 people reaching safety after $30 \mathrm{~min}$. The average evacuation time is $1.11 \mathrm{~h}$, with a standard deviation of $46.5 \mathrm{~min}$ $(69.9 \%)$ and a maximum of $2.78 \mathrm{~h}$, as shown in Fig. $10 \mathrm{~b}$.

The density of the urban layout does not allow for the building of tsunami hills, without demolishing existing buildings. Other possible solutions for enhancing the evacuation capacity in this part of the city (further than relocating the population) thus involve the following: (1) building vertical evacuation structures such as high-raised buildings or pedestrian overpasses (Cedillos 2011) and (2) improving the capacity of the roads and constructing additional bridges.

As mentioned above, representatives from the local NGO Kogami expressed their scepticism regarding building vertical evacuation structures in the city, especially highraised building, as they fear the population would not trust climbing such structures after a large earthquake. Therefore, they advocate for the construction of new bridges and the widening of the roads to high ground. For that, the first scenario analysed for the southern part of Padang involved the addition of five pedestrian bridges (Fig. 9) in the southernmost area crossing the Batang Arau (scenario 6). This scenario resulted in 71,447 people reaching safety after $30 \mathrm{~min}$, corresponding to the $34.0 \%$ of the population. The maximum evacuation time is $2.71 \mathrm{~h}$, and the average is $57.6 \mathrm{~min}$, with a standard deviation of 41.4 min $(71.8 \%)$. The distribution of the arrival times is shown in Fig. 10c.

The next scenarios for the southern part included five bridges as those assumed in scenario 5 but doubled in width, plus the widening of all the roads (and relative bridges) leading to
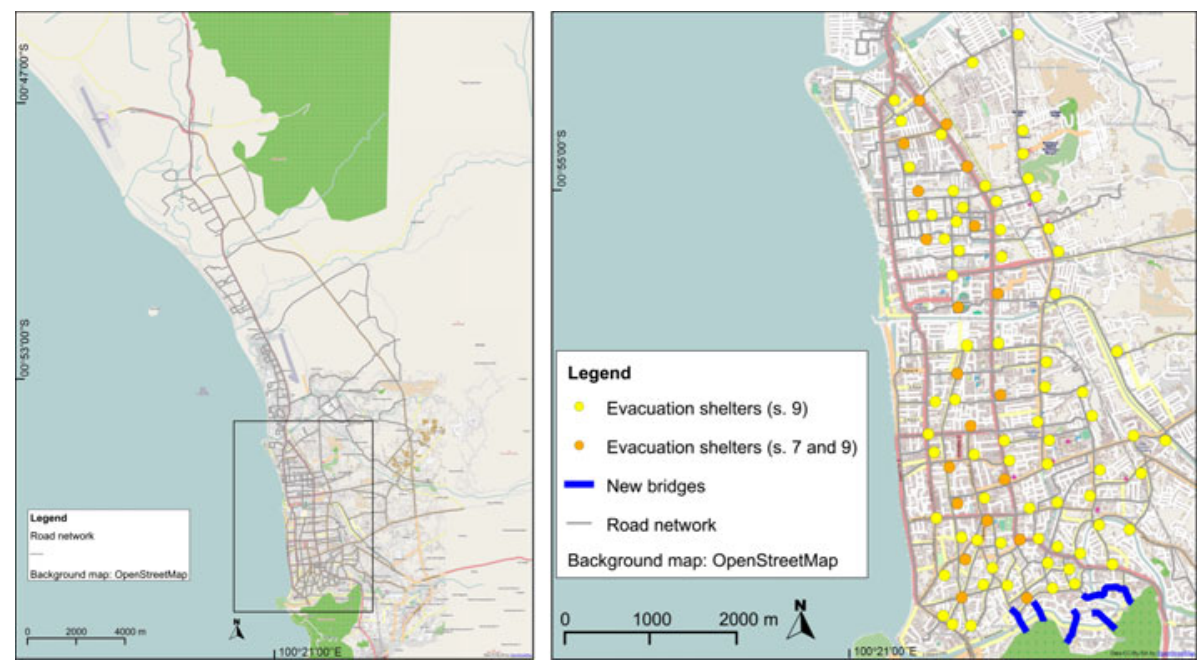

Fig. 9 Potential interventions for the southern part of Padang: vertical evacuation buildings assessed in scenario 9 (orange); vertical evacuation buildings proposed in scenario 11 (orange and yellow); and potential new bridges (blue) 
(a)

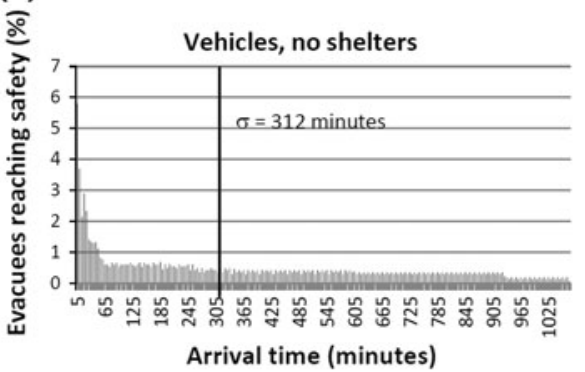

(c)

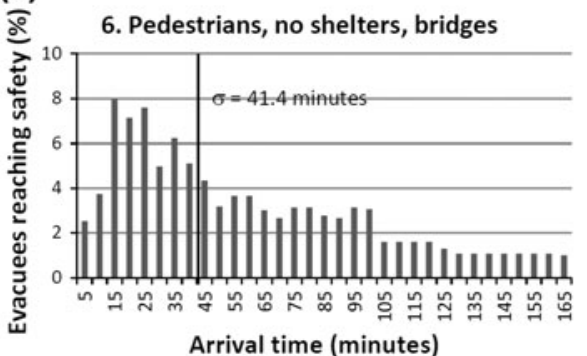

(e)

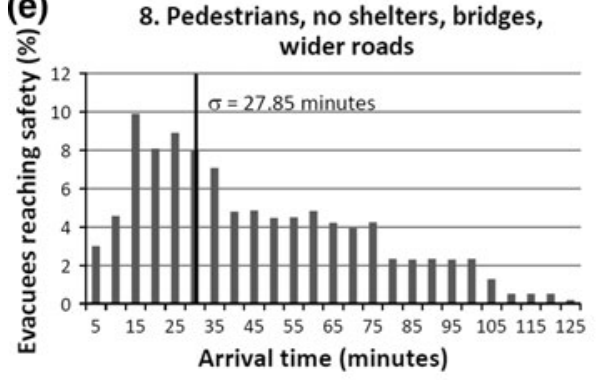

(g)

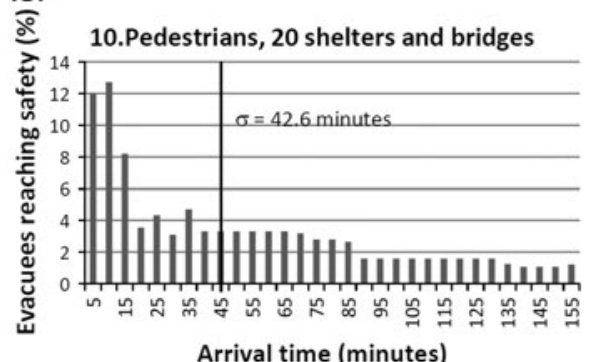

(b)

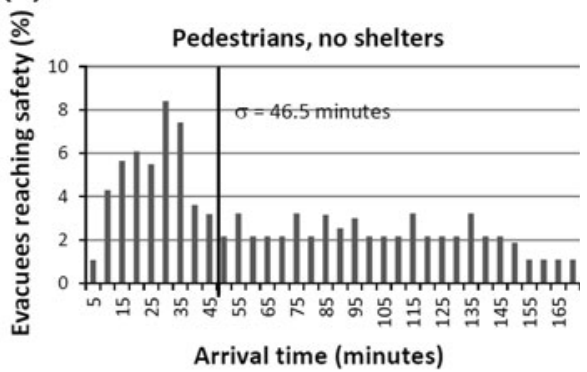

(d)

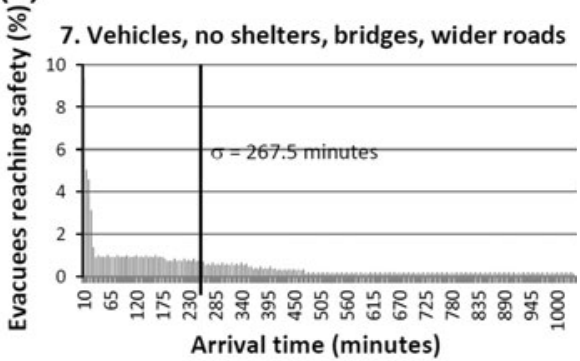

(f)

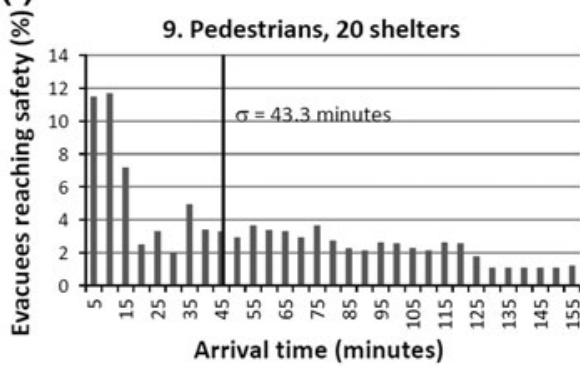

(h)

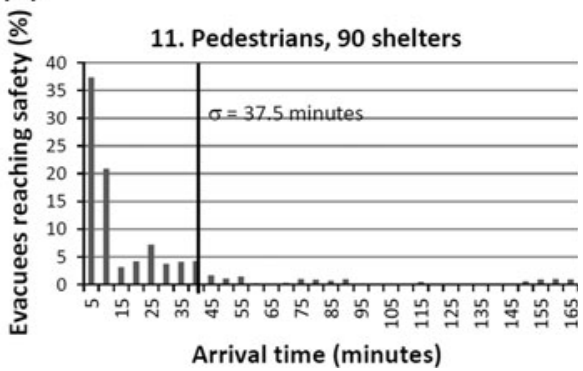

Fig. 10 Distribution of the arrival times resulting from the modelling scenarios implemented for the southern part of Padang. The black lines indicate the values of the standard deviation of the arrival time (min)

high ground (Jalan Nipah, Jalan Husni Thamrin, Jalan Air Camar, Jalan Lubuk Begalung, Jalan Proklamasi, Jalan Tluku Umar, Jalan Doktor Sutomo, Jalan Andalas, Jalan Lolongkaran Raya, Jalan Gaya Mada Jalan Raya Siteba and Jalan Khatib Sulaimah). Clearly, 
widening all these roads would be a very costly intervention, and this would also require demolishing existing buildings in some locations. Both the vehicular evacuation (scenario 7) and pedestrian evacuation (scenario 8 ) were analysed. The scenario in which the population is assumed to evacuate by vehicles (scenario 7) resulted in 51,243 (24.6\%) people evacuating within the first $30 \mathrm{~min}$. The average evacuation speed is $4.23 \mathrm{~h}$, with a standard deviation of $4.46 \mathrm{~h}(105.5 \%$, Fig. 10d) .For the scenario assuming only pedestrian evacuation (scenario 8), 89,281 people (42.2\% of the population of south Padang) evacuate within $30 \mathrm{~min}$. The average evacuation time is $43.2 \mathrm{~min}$, while the maximum evacuation time is $2.03 \mathrm{~h}$, with a standard deviation of $27.85 \mathrm{~min}(64.7 \%)$, as shown in Fig. 10e.

Another scenario (scenario 9) was designed to appraise the effectiveness of vertical evacuation buildings. These should be more than four floors high, capable of resisting the tsunami wave, and the staircases should be easily accessible by the evacuees. It was assumed that each building has seven floors (e.g. three floors and a terrace above the potential tsunami height), each of them measuring $500 \mathrm{~m}^{2}$. Each building is therefore assumed to be able to host about 2,000 people. Twenty evacuation structures are assumed to be built close to the main crossroads along two imaginary rows, the first row about $500 \mathrm{~m}$ from the shoreline, while the second row about 1,500 m from the coastline (Fig. 9). Such structures could host about 40,000 of the 210,421 evacuees. A buffer of \pm 200 people per structure have to be considered for computational reasons. The results show that 80,266 people (38.1\% of the population) would evacuate after $30 \mathrm{~min}$. The calculated maximum evacuation time is $2.58 \mathrm{~h}$, with an average evacuation time of $53.4 \mathrm{~min}$ and a standard deviation of $80.7 \%$ (43.3 $\mathrm{min}$ ). The distribution of arrival times in Fig. 10f shows a second peak in the distribution, due to the delayed arrivals of those evacuees that have to select another shelter, as they found the one closer to them to be full. The evacuees use all the structures to their full capacity.

The intervention scenario 10 is a combination of the previous two. Widening of the roads is not economically feasible and has shown not to be particularly effective; thus, this intervention was discarded. The building of five new bridges in the southern part (connecting the low-lying area with Gunung Padang) is considered, together with the twenty vertical evacuation buildings, such as those considered in scenario 9. This scenario showed that $43.9 \%$ of the population $(92,388$ people) are able to evacuate within the first $30 \mathrm{~min}$. The maximum evacuation time is $2.58 \mathrm{~h}$, while the average evacuation time is $49 \mathrm{~min}$, with a standard deviation of $42.6 \mathrm{~min}$ (86.9\%, Fig. 10g). According to the model, 43,370 people evacuate to the vertical evacuation shelters, while 43,012 people evacuate through the 'new' bridges and 124,038 evacuates to high ground. This is coherent with the modelling set-up, which assumes that the first choice for the evacuees is the one that is closer to them.

In the last scenario analysed (scenario 11), we try to introduce a number of vertical evacuation buildings that can potentially host most of the population, although this would mean building an evacuation 'tower' almost at each crossroad. We assume 90 structures (Fig. 9) that could therefore host about 180-200,000 evacuees in total. This scenario resulted in $76.6 \%$ of the population (161,253 people) reaching a shelter or the high ground within $30 \mathrm{~min}$. The average evacuation rate is $24.6 \mathrm{~min}$, with a standard deviation of 37.9 min $(154.7 \%)$ and a maximum evacuation time of $2.77 \mathrm{~h}$ (Fig. 10h).

The summary of the results is reported in Table 4 .

\section{Discussion}

The results show that with no interventions, less than $20 \%$ of the population of Padang would be able to evacuate within $30 \mathrm{~min}$ from the earthquake, if evacuating by vehicle. 


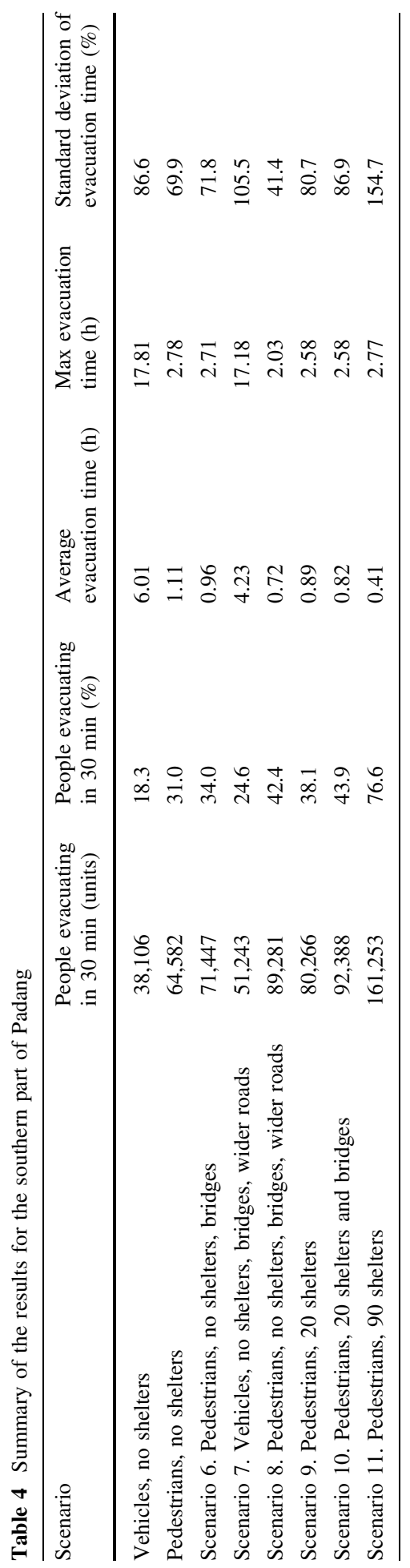



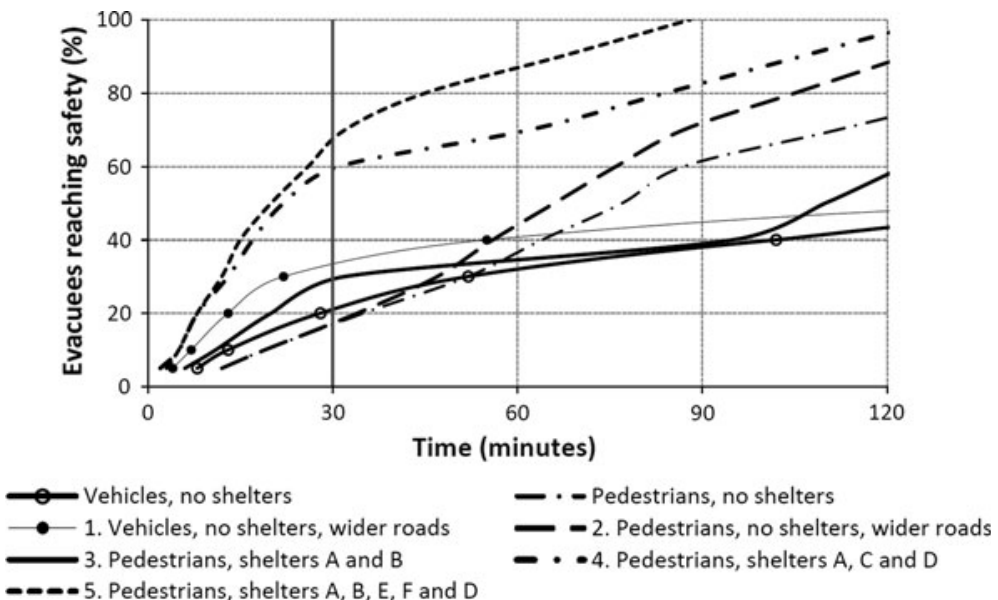

Fig. 11 Evacuation curves for the northern part of the city
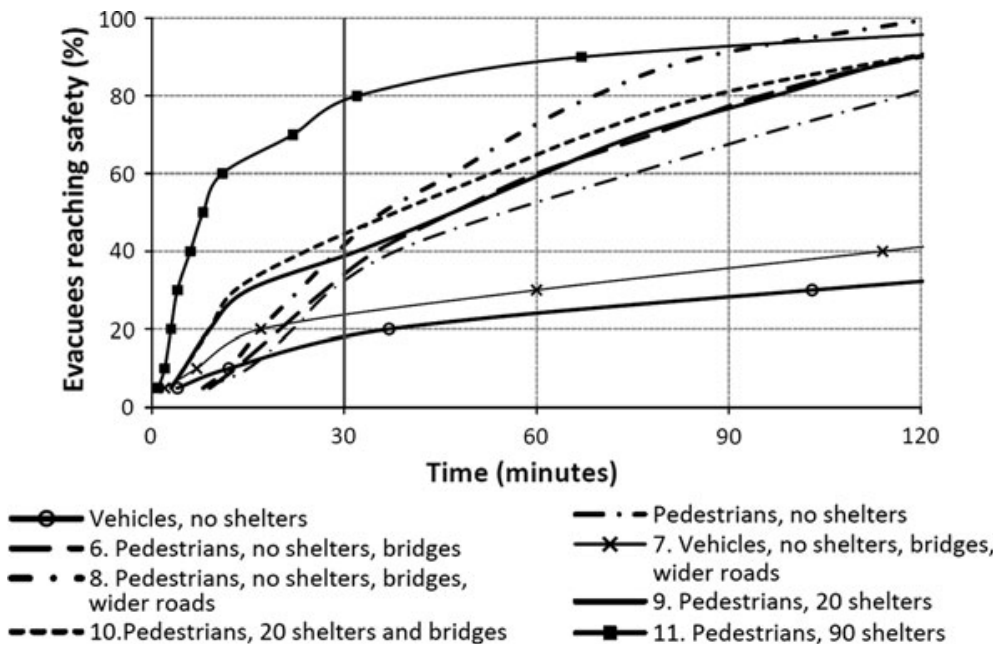

Fig. 12 Evacuation curves for the southern part of the city

These results are obtained under the assumption that everybody leaves immediately after the earthquake, knows the shortest evacuation path and starts moving towards high ground without stopping along the way. Behaviours such as waiting for confirmation (Mileti and Sorensen 1990), diverting to retrieve more information (Sharma et al. 2009) or delaying the evacuation to collect goods or to reach family members (Drabek 1986) are common during an evacuation. Thus, this result is likely to overestimate the number of people that are able to reach safety within $30 \mathrm{~min}$. The model was able to reconstruct the congestion patterns observed during the evacuation of the 11 April 2012.

\subsection{Comparison of vehicular and pedestrian evacuation}

To compare the different scenarios, we look at the evacuation curves for the northern (Fig. 11) and the southern (Fig. 12) part of the city. If the people are assumed to evacuate 
by foot, more than $25 \%$ of the population can reach safety within 30 min, potentially showing that evacuating by foot is faster due to the traffic conditions. This depends, however, on the population density and the distance to be covered. In the southern part of the city, the population density is high compared to the capacity of the roads; at the same time, the distance to high ground is relatively low, with a maximum of $5 \mathrm{~km}$. Here the population reaching high ground by foot after $30 \mathrm{~min}$ is about $30 \%$; thus, more than $10 \%$ of the people reach safety in $30 \mathrm{~min}$ in the vehicular evacuation scenario. On the other hand, in the northern part of the city, about $12 \%$ less people reach safety after $30 \mathrm{~min}$ if evacuating by foot, compared to the scenario assuming a vehicular evacuation. This is because in the northern part of the city, the vehicular traffic jams require an initial time to develop, allowing those who first evacuate to avoid the jams, and the delay due to the traffic is partly compensated for by the long distance that the pedestrians have to cover to reach high ground (about $8 \mathrm{~km}$ ). Due to the lower population density and total number of people in the northern part, the traffic jams require about 30 min to fully develop (Fig. 11), while in the southern part, the roads gridlock almost instantaneously after the beginning of the evacuation (Fig. 12).

\subsection{Analysis of the interventions for the northern part of the city}

For the northern part of Padang (Fig. 11), the most effective interventions are those in which large evacuation hills are assumed (scenarios 3 and 4). These scenarios show an increase of $40 \%$ in the population that reach safety within the first 30 min comparing with the baseline scenarios. This is because the evacuees are more likely to reach one of these shelters directly or after having tried to go to the smaller hills, which are located at short distances from the larger evacuation hills. Building larger roads (scenario 1) improves the evacuation rate until the roads are gridlocked, which means that the vehicles are still blocked on the roads for many hours. As some of the evacuation roads are parallel to the shoreline, the people stuck in vehicles along these roads are very likely to be caught by the incoming tsunami wave.

The results from scenario 2 show that the benefits of building small evacuation hills are limited to the actual capacity of these hills. The evacuation curve (solid line, Fig. 11) is steep until the evacuation hills are 'filled up'. After that, the evacuation rate decreases drastically as the people are turning back to reach other areas of high ground, which is located about $4 \mathrm{~km}$ from the evacuation hills. In fact, after $40 \mathrm{~min}$, a larger evacuation rate is obtained for the scenario in which pedestrians are assumed to evacuate to high ground only, as well as for the scenario in which wider roads are included. The benefit of this intervention would, however, be relevant if the time available to evacuate was $60 \mathrm{~min}$ or more. In Padang, the tsunami could reach the city after $30 \mathrm{~min}$; therefore, the best interventions are those that provide the highest evacuation rate within this time frame. In the case of scenario 2, the two small structures alone can cause an increase of approximately $10 \%$ in the population reaching safety before the tsunami arrives.

\subsection{Analysis of the interventions for the southern part of the city}

Similarly to the situation in northern part, the evacuation rates in the southern part benefit from the presence of the shelter. Again, the benefits of the shelters are limited to the shelters' capacity. In scenario 6 (continuous line, Fig. 12), the higher evacuation rate is obtained until most of the shelters reach their full capacity. At this point, the evacuees who find their 'first-choice shelter' fully employ their time trying to find another shelter. This 
causes the evacuation rate to decrease until all the evacuees start moving towards their final destinations, which mainly is high ground. As expected, the highest evacuation rate is obtained in the scenario with a total shelter capacity comparable to the total number of people at risk (scenario 11). The effect of the shelters is critical in the first $30 \mathrm{~min}$ of the evacuation. This can certainly be improved if the evacuees have a pre-assigned shelter, thus avoid wasting time trying to reach a shelter that is already full. In the subsequent time (40-90 $\mathrm{min}$ ), and because the distance to cover is relatively low (maximum $5 \mathrm{~km}$ ), the introduction of high-capacity roads and bridges improves the evacuation rate (scenario 8) for pedestrian evacuation, as the evacuees are not constrained by the ingress rate of the evacuation buildings, which inevitably delays the evacuation. On the other hand, this model does not consider different evacuation speed due to the demography, while in reality a portion of the population might not be able to cover the distance to high ground. However, this is also the case of the evacuation into high-raised buildings, in which the evacuees would need to climb at least to the fourth floor. The effectiveness of building many evacuation 'towers' is also highly dependent on the quality of the structures, which needs to withstand a M8.9 earthquake and a tsunami of several metres. In Padang, although a building code exists, many buildings were destroyed during the past earthquakes, many of which were newly constructed (World Health Organisation 2007; Alarcon et al. 2009; World Health Organisation 2009). If the evacuation structures are destroyed during the earthquake, they will further block the evacuation roads and leave the population unprepared. As the Great East Japan tsunami sadly showed (e.g. EERI 2011), inadequate tsunami shelters can prove fatal for evacuees searching refuge in such structures. These people could have potentially reached high ground. Therefore, building structures that might potentially be destroyed either by the earthquake or by the tsunami can have worse consequences than building no structures at all.

As discussed above, due to the high population density, the roads get gridlocked almost instantaneously, which explains the very low evacuation rate for the vehicular evacuation scenario. Constructing more bridges and widening the roads leading to high ground does not improve the situation significantly, as the main traffic is generated within the roads closer to the coastline, which could not be widened without demolishing many residential buildings.

\subsection{Specific conclusions for the city of Padang}

For the city of Padang, pedestrian evacuation is certainly to be preferred to vehicular evacuation, as it results in considerably higher evacuation times. However, the results show that evacuating to high ground within $30 \mathrm{~min}$ is not achievable for $70-80 \%$ of the population in the current situation. Widening of roads and building of bridges are relatively ineffective due to the large distance that has to be covered in a short time and would only have a decisive impact if a longer evacuation time (more than $60 \mathrm{~min}$ ) was available.

Given the distances to high ground, the evacuation rate in the first $30 \mathrm{~min}$ is strongly dependent on the presence/absence of evacuation shelters. The effectiveness of these shelters is, however, only limited to the actual capacity of the structures. Building small structures has only a very limited impact on the overall evacuation rate. However, this study shows that building structures with an inadequate capacity does not have a negative impact on the evacuation rate, even if some of the evacuees might waste some time trying to reach a structure that is already full. This supports the argument that building few small structures is better than building no structures at all. Regarding evacuation 'towers', the uncertainties in the construction quality of the high-raised buildings might need to be 
considered as they might lead to a worse scenario than one in which no structures are built. During the consultation with a local NGO, it was also noted that the people might not trust such structures, and in this case, they would be completely ineffective. Further research could be carried out in this sense by analysing the benefits of 'tsunami decks', which can be described as the combination of a pedestrian bridge and a tsunami tower (Muhari et al. 2012). Although with limited capacity, these structures are more easily accessible than a regular evacuation tower and might overcome people's reservations in entering to a building after a strong earthquake.

The results presented here were obtained under two assumptions: (1) people evacuate immediately after the earthquake and (2) people go straight to the nearest evacuation shelter. Both these assumptions lead to shorter evacuation times. Still, even if the evacuation structures are built, roads are enlarged and bridges are constructed, about $20 \%$ of the population would still be unable to reach safety by the time the tsunami arrives. For Padang, this means about 70,000 people would be in danger. These results were also calculated using the present population scenario. In view of the annual rate of population growth in Indonesia (2\% in 2009 (Asian Development Bank 2010)), the number of expected losses from a potential tsunami will no doubt increase. Building evacuation shelters could potentially live in the present situation, but this solution is not sustainable in the medium to long term as further shelters should be continuously built as the population increases. Also, no solution can save $100 \%$ of the people, as evacuating densely populated areas in such a short time is a disruptive event that alone can potentially generate many casualties. Finally, even if everybody could reach a safe area on time, the tsunami will always destroy people's houses and livelihoods. Enforced regulations for land use planning that take into account the tsunami risk are therefore necessary to prevent further urban development for the tsunami-prone areas.

\subsection{Recommendations for the implementation of risk reduction options in Padang}

1. The results from this study show that, in the current situation, evacuating the population of Padang within $30 \mathrm{~min}$ is unrealistic. The time available is extremely limited, and this constitutes a challenge for any early warning system. While working on strengthening the existing system is vital for operational reasons, it may take years before this system makes it possible for the warning to be rapidly disseminated and acknowledged by the population (i.e. within minutes). Any delay in this compromises the life of tens of thousands of people. The message that needs to be disseminated now is for people to evacuate as soon as a strong earthquake is felt. This will inevitably cause false alarms, but it can be paired with a strong education campaign to foster the understanding that this is the only possible chance of survival if a large tsunami occurs.

2. Vehicles should not be used to evacuate, especially in the southern part of the city. Here evacuating by foot can increase the number of people reaching the high ground in 30 min by over $11 \%$, compared to if they were evacuating by vehicles. Given the distance to cover and the limited time, widening the roads and building bridges does not impact greatly on the vehicular or the pedestrian evacuation rates.

3. Evacuating by foot should be strongly recommended to the residents, also using the results of the simulation to demonstrate the advantages of pedestrian evacuation and the disadvantages of vehicular evacuation.

4. In the current situation, less than $20 \%$ of people can be realistically expected to reach high ground within $30 \mathrm{~min}$. Interventions need to be implemented urgently. 
5. In the northern part of the city, the most effective intervention is to build evacuation hills whose capacity is enough to host the entire population living on the coast (scenario 5). Extensive work has been carried out by GHI in the design of the structures and granting permission for the use of the land; thus, funding seems the only barrier for the implementation of this intervention.

6. In the southern part, where the areas to build evacuation hills cannot be identified, the most effective option (on paper) would be to build at least 90 vertical evacuation buildings, each with the capacity to host about 2,000 people (scenario 11). However, budgeting for building such structures, ensuring that they are earthquake and tsunami proof, and overcoming the diffidence of the population are major issues that make the implementation of this solution unrealistic in the short (5-10 years) term. Building bridges and widening roads (scenario 8) might (arguably) be perceived as relatively easy to implement, but the effectiveness of this intervention is small. In Southern Padang no realistic solution has been found to allow more than $30 \%$ of the population to reach safety on time. This, however, does not mean that nothing should be done. Any intervention that can potentially save even few thousands of lives (such as shelters and bridges to high ground) should be implemented immediately, bearing in mind that the only robust solution for this part of the city is for people to live away from the tsunami-prone area.

7. The implementation of the most effective scenarios can save many lives. However, should these interventions be realised, many casualties are still to be expected, and houses and livelihoods would be anyway destroyed by the tsunami. The high rate of population growth can only worsen this situation. It also is necessary to act politically by setting up and enforcing regulations for land use planning that take into account the tsunami risk, preventing further urban development for the areas that can be affected by a tsunami.

\subsection{General conclusions and lessons relevant to other areas at risk}

This paper describes the results of a bespoke evacuation model developed for the city of Padang, Indonesia. The model represents the local traffic patterns, typical of those of many Southeast Asian cities and was used to appraise the impact of different evacuation modes. The results of this analysis showed that evacuation by foot is faster than by vehicle, in areas in which the road network is dense and the roads' capacity is low. Different intervention scenarios for risk reduction were developed in consultation with the stakeholders, and the effectiveness of such interventions was appraised.

Lessons from this research can be used for application in other areas in Southeast Asia where the traffic patterns similar to those in Padang and where the distance to safety is greater than $4-5 \mathrm{~km}$.

When appraising the benefits of vertical evacuation structures, the results showed that the evacuation rate improves only until the structures are filled. In fact, the rate of evacuation is strongly influenced by the capacity of the evacuation structures, especially in the first $30 \mathrm{~min}$. To evacuate areas where the evacuation time is shorter than $1 \mathrm{~h}$, the most effective solution is to build large (preferably over-dimensioned) vertical evacuation shelters, such as evacuation hills. The effectiveness of building a large number of small shelters is strongly dependent on the evacuees being evenly distributed towards the shelters (achieved by previously informing and training them to recognise which shelter they should use). However, when the evacuation time is short, the evacuation plan needs to be 
robust, thus cannot be highly sensitive to training or evacuees' compliance to pre-assigned routes or complex instructions. That is a further support for large, obvious evacuation structures rather than many small buildings. Where the available evacuation time exceeds $2 \mathrm{~h}$, pedestrian evacuation outside the area at risk can be prospected, given that the road infrastructure is adequate in terms of capacity and redundancy. This option can avoid vehicular traffic congestion, which also has the advantage of easily allowing emergency services to access the area at risk and assist the evacuees.

It is important to remark that mass evacuation should not be the only strategy for tsunami risk reduction in regions where the tsunami risk is high and the arrival time is shorter than few hours. Economic losses and fatalities cannot be avoided only by evacuation, and the communities coping capacities to recover from the disaster should also be considered. Comprehensive risk-based strategies considering land use planning and regulations should be developed and adopted, taking into account risks from different natural hazards, including tsunami.

In fact, city planning should be accompanied by sound risk assessments, including modelling the hazard but also assessing possible consequences to the population. Analysing the feasibility of evacuating an area before embarking in new developments should be included in feasibility studies, especially for tsunami-prone areas. In general, local governments should take into account risk from disasters and include disaster risk reduction measures in cities' development plans.

Acknowledgments The authors would like to acknowledge and thank the consultees that participated in this study, specifically Badan Nasional Penanggulanggan Bencana, Badan Penanggulangan Bencana Daerah, Kogami, the Australia-Indonesia Facility for Disaster Reduction and Mercy Corps. We would also like to thank Dr Li Lin Lin, Dr Meya Yanger Walling, Nicole Shufelt, MSc and Dr Annie Winson (Earth Observatory of Singapore, Nanyang Technological University) for providing their valuable comments on the research work and the paper.

\section{References}

Alarcon J, Mulyani R, Whittle, Siau JD (2009) The Padang, Sumatra, Indonesia Earthquake of 30 September 2009. In: Wilkinson S (ed) field report from the Earthquake Engineering Field Investigation Team (EEFIT), London

Andriani DC (2012) Gempa Susulan Memaksa Warga Padang Mengungsi. Available from: http://www.zamrud tv.com/sumbar-4510-gempa-susulan-memaksa-warga-padang-mengungsi.html. Accessed 17 April 2012

Asian Development Bank (2010) Key Indicators for Asia and the Pacific 2010. Mandaluyong City, Philippines

Avouac JP, Konca AO et al (2008) Partial rupture of a locked patch of the Sumatra megathrust during the 2007 earthquake sequence. Nature 456(7222):631-635

Bappenas and BNPB (2010) National Action Plan for Disaster Risk Reduction (NAP-DRR) 2010-2012. Available at www.bnpb.go.id/website/file/pubnew/99.pdf

Borrero JC, Sieh K, Chlieh M, Synolakis CE (2006) Tsunami inundation modeling for western Sumatra. Proc Natl Acad Sci USA 103(52):19673-19677

BPS Kota Padang (2005) Kecamatan dalam angka—subdistricts in numbers. Statistical bureau (BPS) Kota Padang, Padang

BPS Kota Padang (2010) National Statistics Kota Padang

Brooks O (2010) Tsunami alert, beating Asia's next big one. Nanyang Technological University, Singapore

Cedillos V (2011) Report on crucial need for Tsunami evacuation solutions for Padang. GeoHazards International Report, West Sumatra

Chandra S, Kumar U (2003) Effect of lane width on capacity under mixed traffic conditions in India. J Transp Eng 129(2):155-160

Departemen Pekerjaan Umum (1997) Manual Kapasitas Jalan Indonesia (Indonesian Highway Capacity Manual) Direktorat Jenderal Bina Marga, Indonesia 
Di Mauro M, Lees M, Megawati K, Huang Z (2013) Pedestrian-vehicles interaction during evacuation: agent-based hybrid evacuation modelling of Southeast Asian cities. Pedestrian and Evacuation Dynamics 2012

Drabek TE (1986) Human system responses to disaster: an inventory of sociological findings. Springer, New York

EERI (2011) The March 11, 2011, Great East Japan (Tohoku) Earthquake and Tsunami: societal dimensions, EERI special earthquake report. Available at eqs.eeri.org. Accessed 6 August 2012

FEMA (2008) Guidelines for design of structures for vertical evacuation from Tsunamis, Federal Emergency Management Agency report P646

Gayer G, Leschka S, Nohren I, Larsen O, Gunther H (2010) Tsunami inundation modelling based on detailed roughness maps of densely populated areas. Nat Hazards Earth Syst Sci 10(8):1679-1687

GITEWS (2010) Tsunami Evacuation Map Padang. Available at http://www.gitews.org/tsunami-kit/en/id_ tsunami_evacuation_map_padang.html. Accessed 6 August 2012

Gordon RL (1969) Technique for control of traffic at critical intersections. Transp Sci 3(4):279-288

Helbing D, Treiber M (1999) Numerical simulation of macroscopic traffic equations. Comput Sci Eng 1(5):89-99

Hoang TL, Miska M et al (2010) Simulating motorbike dominated Traffic. 12th World Conference on Transport Research. Lisbon, Portugal

Hoogendoorn SP, Daamen W (2005) Pedestrian behavior at bottlenecks. Transp Sci 39(2):147-159

Hoppe M, Mahadiko HS (2010) 30 minutes in Padang-lessons for tsunami early warning and preparedness from the earthquake on 30 September 2009. GTZ-GITEWS project publication

Imamura F, Muhari A et al (2012) Tsunami disaster mitigation by integrating comprehensive countermeasures in Padang city, Indonesia. J Disaster Res 7(1):48-64

Kerner BS (2009) Introduction to modern traffic flow theory and control. Springer, Berlin

Korhonen T, Hostikka S, Heliovaara S, Ehtamo H (2010) FDS+Evac: an agent based fire evacuation model. Pedestr Evacuation Dyn 2008:109-120

Kretz T, Grunebohm A et al (2008) Upstairs walking speed distributions on a long stairway. Saf Sci 46:72-78

Lammel G, Grether D et al (2010) The representation and implementation of time-dependent inundation in large-scale microscopic evacuation simulations. Transp Res Part C Emerg Technol 18(1):84-98

Latané B, Williams K, Harkins S (1979) Many hands make light the work: the causes and consequences of social loafing. J Pers Soc Psychol 37(6):822-832

Lee DC (2006) Proof of a modified Dijkstra's algorithm for computing shortest bundle delay in networks with deterministically time-varying links. IEEE Commun Lett 10(10):734-736

Luke S, Cioffi-Revilla C, Panait L, Sullivan K, Balan G (2005) MASON: a multi-agent simulation environment. Simul Trans Soc Model Simul Int 82(7): 517-527

MapAction (2009) Indonesia: Sumatra earthquake affected area, population density in 2003, Available at http://ochaonline.un.org/OchaLinkClick.aspx?link=ocha\&docId=1132551. Accessed 6 August 2012

McCloskey J, Antonioli A, Piatanesi A, Sieh K, Steacy S et al (2008) Tsunami threat in the Indian Ocean from a future megathrust earthquake west of Sumatra. Earth Planet Sci Lett 265(1-2):61-81

Mileti DS, Sorensen JH (1990) Communication of emergency public warnings: a social science perspective and state-of-the-art assessment. Oak Ridge National Laboratory for the Federal Emergency Management Agency, Oak Ridge Tennassee

Muhari A, Imamura F et al (2010) Tsunami mitigation efforts with pTA in West Sumatra province, Indonesia. J Earthq Tsunami 4(4):341-368

Muhari A, Imamura F, Koshimura S (2012) Tsunami-deck: an introduction concept for a new type of vertical tsunami evacuation shelter. Proceedings of the 59th Conference on Coastal Engineering, 2012 (available at http://jglobal.jst.go.jp/public/20090422/201202246025296440\#jgid201202246025296440)

Natawidjaja DH, Sieh K et al (2006) Source parameters of the great Sumatran megathrust earthquakes of 1797 and 1833 inferred from coral microatolls. J Geophys Res 111(B06403):1-37

Parker DJ, Priest SJ, Tapsell SM (2009) Understanding and enhancing the public's behavioural response to flood warning information. Meteorol Appl 16:103-114

Post J, Wegscheider S et al (2009) Assessment of human immediate response capability related to tsunami threats in Indonesia at a sub-national scale. Nat Hazards Earth Syst Sci 9(4):1075-1086

Sharma U, Patwardhan A, Parthasarathy D (2009) Assessing adaptive capacity to tropical cyclones in the East coast of India: a pilot study of public response to cyclone warning information. Climatic Change 94:189-209

Sieh K et al (2008) Earthquake Supercycles Inferred from sea-level changes recorded in the corals of West Sumatra. Science 322(5908):1674-1678 
Taubenbock H, Goseberg N et al (2009) "Last-Mile" preparation for a potential disaster-interdisciplinary approach towards tsunami early warning and an evacuation information system for the coastal city of Padang, Indonesia. Nat Hazards Earth Syst Sci 9(4):1509-1528

The Eclipse Foundation (2012) The eclipse foundation open source website, www.eclipse.org

Trajfel H (1978) Social characterisation, social identity and social comparison. In Tajfel H (ed) Differentiations between social groups, Academic Press: New York pp 61-76

Turner RH (1964) Collective behaviour. In: Faris REL (ed) Handbook of modern sociology. Rand-McNally, Chicago, pp 382-425

USGS (2010) The Padang, Indonesia Earthquake of 2009 http://gallery.usgs.gov/videos/283

USGS (2012) M8.6 and M8.2 Northern Sumatra, Indonesia earthquakes of 11 April 2012, available at http://earthquake.usgs.gov/earthquakes/eqarchives/poster/2012/20120411.php. Accessed 6 August 2012

Weidman U (1993) Transporttechnik der Fussganger., in Schriftenreihe des IVT, ETH: Zurich

World Health Organisation (2007) Earth Quake in Padang, West Sumatra Province, Indonesia, Emergency Situation Report 1, 6 March 2007. Available at www.who.int/hac/crises/idn/sitreps/en/index.html. Accessed 6 August 2012

World Health Organisation (2009) Earthquake in Padang, West Sumatra Province, Republic of Indonesia, Emergency Situation Report (ESR-16), 3 November 2009. Available at www.who.int/hac/crises/idn/ sitreps/en/index.html. Accessed 6 August 2012. 